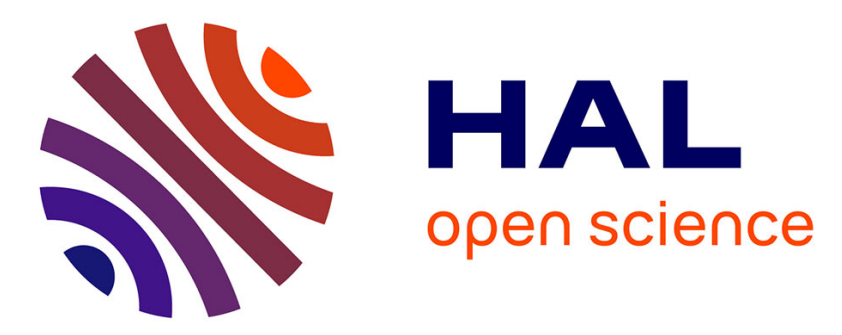

\title{
Culture matérielle et appartenances ethniques: quelques questions posées par les nécropoles d'El-Deir (oasis de Kharga, Égypte)
}

Gaëlle Tallet

\section{- To cite this version:}

Gaëlle Tallet. Culture matérielle et appartenances ethniques: quelques questions posées par les nécropoles d'El-Deir (oasis de Kharga, Égypte). Identité ethnique et culture matérielle dans le monde grec, Dec 2010, Besançon, France. pp.219-255. hal-01368909

\section{HAL Id: hal-01368909 \\ https://hal.science/hal-01368909}

Submitted on 17 Nov 2016

HAL is a multi-disciplinary open access archive for the deposit and dissemination of scientific research documents, whether they are published or not. The documents may come from teaching and research institutions in France or abroad, or from public or private research centers.
L'archive ouverte pluridisciplinaire HAL, est destinée au dépôt et à la diffusion de documents scientifiques de niveau recherche, publiés ou non, émanant des établissements d'enseignement et de recherche français ou étrangers, des laboratoires publics ou privés. 


\section{Culture matérielle et appartenances ethniques : quelques questions posées par les nécropoles d'El-Deir (oasis de Kharga, Égypte)'}

« La seconde loi de la thermodynamique nous enseigne, en effet, qu' un système fermé, totalement homogène, cesse de produire du travail perceptible de l'extérieur. »

G. Devereux, «L'identité ethnique. Ses bases logiques et ses dysfonctions (1970) », in : Devereux 1972, 131-168, 165.

C'est « uniquement» par la considération de la loi physique de l'entropie que G. Devereux dit être parvenu à la conclusion que «la diversité des cultures, et des identités ethniques, était indispensable à la civilisation humaine $\gg^{2}$. Mais le parallèle établi avec l'énoncé de cette loi porte en soi davantage que le constat de la nécessité de la diversité, de l'hétérogénéité, pour la pérennité des systèmes physiques comme des sociétés et des cultures : il souligne l'importance de la perception depuis «l'extérieur » $\mathrm{du}$ « travail » produit par le « système », et pose ainsi la question des modalités mêmes d'appréhension de la diversité des cultures depuis cet « extérieur ».

Le débat sous-jacent est double. Il porte tout d'abord sur la définition de l'ethnicité et des identités ethniques, dont les travaux de G. Devereux, contemporains de ceux de Fr. Barth, reflètent l'importance dans les sciences sociales et l'anthropologie à partir des

\footnotetext{
1 Dans la préparation de cette contribution, j' ai bénéficié des conseils et des suggestions des céramologues Pascale Ballet, Sophie Brones, Catherine Defernez et Sylvie Marchand, que je tiens à remercier chaleureusement. Les échanges que nous avons eus ont démontré l'acuité de la question de l'articulation entre culture matérielle et ethnicité, et l'urgence d'une réflexion méthodologique. Je dois beaucoup également aux discussions nourries et continues que j'ai pu avoir avec Françoise Dunand, ancienne Directrice de la mission archéologique d'El-Deir. Toute erreur relèverait toutefois de ma seule responsabilité. Les notices des formes céramiques abordées ont été rédigées grâce aux éléments et aux dessins fournis par Sophie Brones et les plans des tombes du secteur nord-est ont été réalisés par Emmanuelle Devaux (IFPO), que je tiens à remercier également.

2

Devereux 1972, 165.
} 
années 1960. L'articulation de cette réflexion théorique avec une approche archéologique de la culture matérielle est tout aussi délicate qu' inhérente à la démarche archéologique. Elle fait l'objet d'un deuxième débat, qui traverse la théorisation de la discipline archéologique depuis son origine et en particulier depuis l'ouvrage de V. Gordon Childe, Man Makes Himself, en 1936 : c'est la question de l'articulation entre objet et sujet, entre la culture matérielle, objective - le monde matériel que nous habitons -, et la dimension subjective de la culture d'une société, au sens anthropologique - le monde tel que cette société se le représente, notamment à travers le langage ${ }^{3}$.

Comment appréhender, à travers les objets matériels produits par une société, des contenus aussi subjectifs que ceux d'ethnicité et d'appartenance ethnique, c'est donc là une question à la fois théorique et pratique.

Pour poser le cadre théorique, je partirai ici d'une définition assez simple de la culture matérielle, proposée par K. Kristiansen : il s'agit du « monde matériel » d'une société, des « conditions de vie matérielle » d'une population, qu' elle produit, reproduit et consomme en permanence, de la nourriture et des déchets aux bâtiments, routes et outils $^{4}$. La culture matérielle fait donc partie, aux côtés des croyances, des mythes, des idées et des valeurs, d'un ensemble de réalisations des groupes humains qui forme la culture proprement dite, au sens anthropologique. Et, comme le rappelle K. Kristiansen, l'archéologie est la seule discipline qui a pour objectif principal de documenter, classifier et interpréter la culture matérielle pour reconstruire des sociétés, passées ou présentes 5 .

Toutefois, comme l'a exposé S. Jones dans sa récente étude sur « l'archéologie de l'ethnicité », l'idée même que l'ethnicité soit un phénomène accessible à l'enquête archéologique n'est pas admise par tous, au motif que l'archéologie ne saurait fournir un accès direct aux motivations et aux perceptions individuelles ${ }^{6}$. L'ethnicité fait, en effet, intervenir une dimension « subjective », comme l'ont démontré les travaux de F. Barth sur les «frontières » de l'ethnicité . Selon Fr. Barth, un groupe ethnique se définit sur la base de la catégorisation de soi et des autres que proposent eux-mêmes les acteurs du groupe; cette catégorisation de l'individu est censément déterminée par son origine,

\footnotetext{
3 Voir à ce sujet l'exposé synthétique d'A. Jones : Jones 2009.

4 Kristiansen 2009, 5.

5 Kristiansen 2009,6

6 Jones 1997, 124; voir aussi Trigger 1977, 22-23; Trigger 1996, 277.

7 Barth 1969.
} 
réelle ou supposée, et par son milieu, dans le cadre de l'interaction sociale ${ }^{8}$. Les traits importants sont donc ceux qui sont considérés comme significatifs par les acteurs euxmêmes; ils ne sont pas objectifs. La catégorisation ethnique ne repose pas sur une liste de traits, mais sur une organisation, une hiérarchisation de ces traits par les acteurs euxmêmes. Fr. Barth préfère donc laisser de côté le contenu culturel partagé par un groupe pour porter l'acuité de son investigation sur la frontière ethnique qui définit le groupe'. L'identification de critères objectifs d'appartenance à un groupe ethnique, que ces signes soient explicites (vêtement, langue, architecture, style de vie) ou qu'ils reflètent des orientations des valeurs partagées par le groupe (critères d'excellence, de moralité selon lesquels une action est jugée), devient dans cette perspective secondaire. Or, pensera-ton au premier abord, ce sont à ces traits que l'archéologie peut, en l'absence de sources textuelles, prétendre accéder, et non à leur hiérarchisation subjective dans une société.

Comment donc, à partir d'une culture matérielle, peut-on penser l'appartenance ethnique, phénomène dynamique, fondé sur un classement-reclassement des individus de part et d'autre d'une frontière mouvante entre « eux » et «nous $/$ moi $\gg^{10}$ ? À mon sens, en s'intéressant à la constitution de l'appartenance ethnique et à la production de la culture matérielle on peut le faire sous le jour de la négociation continue, dans le cadre de l'interaction sociale. En fondant l'articulation entre ethnicité et culture matérielle sur une relecture du concept d' habitus développé par P. Bourdieu, S. Jones parvient à mettre en place un cadre théorique opérant pour penser le lien entre sujet et objet, entre frontière et contenu ${ }^{11}$. Ce faisant, elle contribue au débat sur la relation de la culture matérielle aux sujets qui la produisent et la consomment, débat nourri par la théorie de la pratique de P. Bourdieu ${ }^{12}$. Il en ressort que la culture matérielle est active et qu'une fois constituée, elle agit en réaction sur le sujet. En effet, dans la production d'objets, les sujets s'engagent dans un processus de fabrication d'eux-mêmes : les objets manifestent l'externalisation des valeurs et des significations négociées par et imbriquées dans les relations sociales. En retour, ces objets contribuent à constituer les relations sociales, le monde matériel

\footnotetext{
$8 \quad$ Barth 1969, 13-15.

9 Dans la même perspective que Fr. Barth, K. Goudriaan a envisagé d'une manière stimulante la question de l'ethnicité en Égypte hellénistique, non pas d'un point de vue biologique, inné, mais comme le produit des interactions sociales : Goudriaan 1988, 8-13.

10 Chabaud 2011.

11 Bourdieu 1972; Jones 1997, 88-90.

12 Voir à ce sujet Jones 2009.
} 
apportant au sujet tout à la fois des contraintes et des opportunités ${ }^{13}$ : ils fournissent le terrain pour d'autres négociations sociales et attributions de valeurs et de significations. Dans le processus d'objectivation, processus par lequel l'expression sociale et individuelle reçoit une forme, objet et sujet entretiennent donc une relation constituante réciproque. Écarter du champ archéologique l'exploration du contenu subjectif de l'ethnicité à travers la culture matérielle me semble donc une contradiction en soi, dans la mesure où la reconstruction d'une société passée ne saurait se fonder uniquement sur des sources textuelles. Bien au contraire, une telle démarche doit s'appuyer sur une lecture de la production matérielle d'une société vue comme un texte plurie ${ }^{14}$, le monde matériel étant véritablement conçu comme un système de signes ${ }^{15}$. L'objet produit par la technique, en tant qu'extériorisation de l'esprit, pour reprendre un concept élaboré par A. LeroiGourhan, peut et doit être retenu comme un objet d'étude de phénomènes subjectifs des sociétés passées ${ }^{16}$.

Une fois ce cadre théorique établi, la mise en œuvre pratique, sur le terrain, de ce programme n'en demeure pas moins complexe. L'articulation de l'ethnicité avec des productions matérielles attribuées à un groupe culturel ou une société est au cœur d'un débat aussi ancien que l'archéologie elle-même, et l'abandon de présupposés objectivistes (tant dans la définition des groupes ethniques que dans l'appréhension des cultures matérielles elles-mêmes) donne au problème toute son acuité : il s'savère difficile de mettre en relation un phénomène subjectif de définition d'un groupe et un assemblage de traits ou d'objets produits par ce même groupe. Si on ne réduit pas l'objet à son statut d'objet, mais si on le perçoit aussi comme signe, le problème est théoriquement résolu. Mais qu'en est-il sur le terrain ?

\section{La colonisation d'un milieu :}

\section{la domination perse en question dans l'oasis de Kharga}

Le site d'El-Deir, au nord-est de l'oasis de Kharga, dans le désert Libyque égyptien, se situe au point de rencontre de cultures et de populations différentes ${ }^{17}$. Il est

\footnotetext{
13 Jones 2009, 98.

14 Tilley 1999 ; Hodder 1989.

15 Preucel \& Bauer 2001 ; Preucel 2006 ; Jones 2009.

16 Leroi-Gourhan 1982.

17 Commencée en 1998, la mission archéologique d'El-Deir est rattachée depuis 2008 à l'université de Limoges (EA 4270), sous ma direction; au sein de cette mission, le programme « Nécropoles » est dirigé par Fr. Dunand.
} 
en effet au cœur d'un réseau caravanier relativement dense, qui relie l'Égypte au Darfour, au sud (Piste des Quarante Jours), et au Fezzan, à l'ouest. Depuis Kharga, où elles se rejoignaient, les pistes poursuivaient vers la Vallée du Nil, soit directement à travers le plateau du désert Libyque jusqu’à Assiout ou Girga-Abydos, soit par le chapelet des oasis du désert occidental. La chronologie du site, occupé de l'époque saïto-perse ( $V^{e}-I V^{e}$ s. av. J.-C., peut-être un peu avant) jusqu'à l'époque chrétienne ( $V^{e}$ s. ap. J.-C.) coïncide avec une période durant laquelle la société égyptienne s'est profondément transformée du fait de la mise en présence durable de groupes culturels et ethniques différents (Égyptiens, Grecs, Juifs, Syro-Palestiniens, Perses, Libyens). La dimension multiculturelle de la société égyptienne au lendemain de la conquête d'Alexandre le Grand et de l'implantation en masse de soldats, mais aussi de civils venus de tous les coins du monde grec, a fait l'objet de nombreuses études. La question peut également se poser en amont, notamment pour l'époque perse. Ainsi, D. Agut-Labordère a étudié l'existence d'une « frontière intérieure » dans la société militaire égyptienne, telle qu'elle se dessine dans les sources disponibles sur la période de restauration du pouvoir indigène entre les deux dominations perses (525-404 puis 342-332 av. J.-C.). Cette société militaire était très nettement fondée sur un mercenariat multi-ethnique et la victoire du Grand Roi perse Artaxerxès III face au roi égyptien Nectanébo II en 343 av. J.-C. a en partie reposé sur une exploitation stratégique des lignes de fracture qui traversaient l'armée égyptienne du milieu du IVe siècle ${ }^{18}$.

La question qui m'occupera ici, celle de la colonisation de l'oasis de Kharga à l'époque de la domination perse, doit se penser en outre dans le cadre spécifiquement oasien et dans celui de ses dynamiques de peuplement, liées quasi exclusivement aux variations des ressources en eau.

$18 \quad$ Agut-Labordère 2008. 


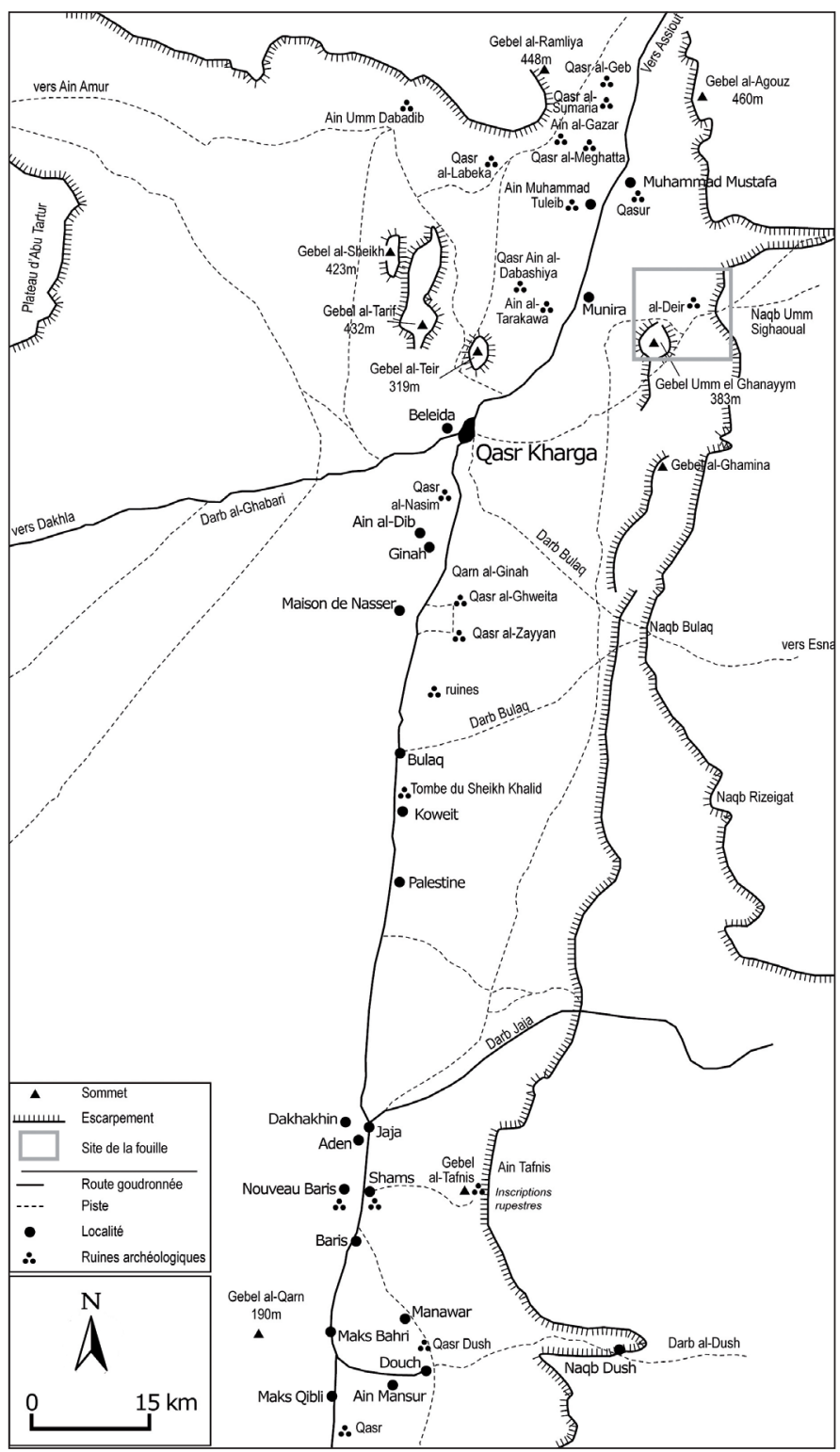

Fig. 1 : I'oasis de Kharga. Carte : R. Garcier d'après Vivian 2009 
La première phase connue correspond en effet aux changements climatiques survenus des environs de 5000 av. J.-C., jusqu'à environ 3300 . À partir de cette phase d'aridification, la seule eau disponible dans le Sahara oriental est devenue une eau fossile, contenue en profondeur dans une immense nappe souterraine de grès nubien. Dans les dépressions que sont les oasis, cette nappe affleure et l'eau, mise sous pression car elle est piégée entre deux couches imperméables, ressort là où une faille lui ménage un passage. Grâce à l'existence de ces résurgences artésiennes, des populations ont trouvé refuge dans les oasis (Kharga, Dakhla, Farafra, Bahariya) tandis que les autres environnements sahariens (zone des playas ou des plateaux) étaient devenus totalement inhospitaliers; ce sont ces points d'eau et ceux, plus au sud, de Bir Tarfawi, Bir Sahara, Bir Hussein, Dunqul, qu'utilisent les pistes caravanières reliant les oasis au Soudan actuel. Ces populations élaborèrent donc des stratégies nouvelles d'accès à l'eau. L'exemple de Douch, au sud de Kharga, montre que dans un premier temps, durant l'Épipaléolithique et le Néolithique, et jusqu'au début de l'Ancien Empire, les hommes se sont contentés d'exploiter l'eau des sources artésiennes ${ }^{19}$. Le géographe B. Bousquet, qui a mené dans les années 1990 un travail précurseur sur l'exploitation de l'eau à Douch, a d'ailleurs associé les différentes phases d'exploitation qu'il a mises en lumière à une culture et un groupe ethnique donnés : il a en quelque sorte ethnicisé la problématique de l'accès à l'eau, en affirmant que le système des puits artésiens était un type « indigène », égyptien, d'aménagement et de gestion de l'eau, fondé sur la dynamique de la crue artésienne. Le système exploite une situation analogue à celle des crues du Nil : une eau sous pression jaillit par des failles et est susceptible d'un régime hétérogène ; toutefois, la crue du Nil est saisonnière, tandis que la montée d'eau artésienne est permanente ${ }^{20}$.

On constate une première phase d'abandon de ces sites vraisemblablement à la fin de l'Ancien Empire, probablement du fait de l'épuisement des sources artésiennes naturelles: l'exploitation de l'artésianisme aurait nécessité le creusement et l'aménagement de puits. Confrontées à cet abaissement - modéré - de la nappe, les populations se sont alors semble-t-il déplacées vers la vallée du $\mathrm{Nil}^{21}$. Une question toujours pendante est de savoir si une présence humaine a été maintenue dans la région entre la fin de la transition vers l'hyperaridité et la deuxième phase attestée de développement dans l'oasis, qui coïncide avec l'introduction d'une nouvelle technique d'adduction d'eau par galeries drainantes, les qanâts, vers le milieu du Ve s. av. J.-C. :

\footnotetext{
19 Briois et al. 2008.

$20 \quad$ Bousquet \& Robin 1999 ; Bousquet 1999, Bousquet 2001.

21 Bousquet 1996, 19-45.
} 
il n'existe aucune trace de peuplement permanent entre ces dates. L'utilisation d'une nouvelle technique d'exploitation des ressources en eau a permis de remettre en culture les plaines qui entourent la colline de Douch (site d'Ayn-Manâwîr) et d'y établir des agglomérations et un temple ${ }^{22}$. Avec l'introduction de cette technique, il est devenu possible de capter les nappes perchées contenues dans les glacis du plateau Libyque. Cette technique d'origine minière serait apparue en Égypte à l'époque de la conquête perse $^{23}$ : l'hypothèse est ancienne mais a été renouvelée lors de colloques organisés par P. Briant au Collège de France; il explore l'hypothèse selon laquelle la technique d'acquisition de l'eau par qanâts se serait répandue dans le bassin méditerranéen à la faveur de la formation de l'empire perse achéménide, vers la fin du VI ${ }^{\mathrm{e}}$ s. av. J.-C. ${ }^{24}$ L'origine exclusivement iranienne de cette technologie n'est toutefois pas démontrée et son implantation n'a pas nécessairement été orchestrée directement par les Grands Rois. Il n'en demeure pas moins que la décoration et l'extension importante du temple d'Hibis (capitale de l'oasis) est datée pour l'essentiel du règne du roi perse Darius Ier, ce qui pourrait être un indice d'un développement soudain de l'oasis de Kharga à cette époque. Les ostraca perses d'Ayn-Manâwîr, un peu plus tardifs (450-370 av. J.-C.), et la datation d'époque perse du temple de Qasr Ghoueita semblent le confirmer. Le rôle des qanâts est évidemment essentiel dans le maintien ou la réimplantation d'une présence humaine au sud de l'oasis, puisqu' elles permettent de s'affranchir de l'aridité et d'irriguer selon des rythmes relativement réguliers. On trouve des qanâts également au nord de l'oasis, à Qasr Zayan ${ }^{25}$, Ayn el-Labakha et 'Ayn Oumm Dabadib ${ }^{26}$.

Mais ce qui est frappant, c'est que là encore, B. Bousquet imprime une lecture culturelle à l'implantation de cette innovation technologique : on retrouve selon lui dans l'oasis de Kharga l'association du relief et du piémont des montagnes d'Asie à la bordure d'une plaine sèche ; le nouveau système d'irrigation par qanât aurait permis la création de véritables jardins d'oasis ou de «paradis » de palmes, relevant selon lui de l'imaginaire géographique perse ${ }^{27}$. Cette vision des choses, largement remise en cause depuis, est révélatrice du lien souvent établi entre culture matérielle et ethnicité.

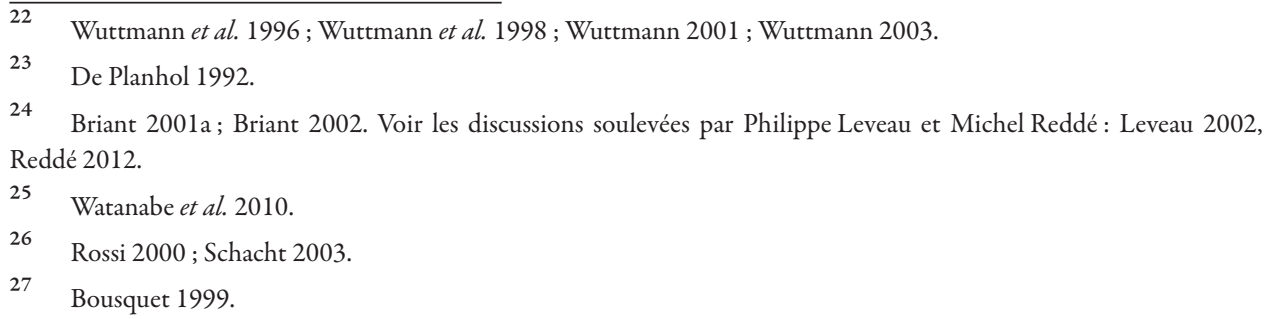


À Douch, la période romaine marque une nouvelle et troisième étape du développement du réseau d'irrigation, avec une extension considérable et systématique du périmètre irrigué ${ }^{28}$ et une mise en réseau des fermes ${ }^{29}$. B. Bousquet y a vu une exploitation « romaine » du terroir, qui aurait imposé une perception fantasmée d'un paysage d'oasis luxuriant et épuisé en un temps relativement court les ressources hydriques disponibles.

On voit donc comment l'analyse des dynamiques de peuplement du milieu oasien et des innovations technologiques liées à la captation de l'eau a pu faire l'objet d'une lecture culturelle, parfois même ethnique, de la part d'un géographe comme B. Bousquet. Le débat a été particulièrement vif pour la phase de colonisation d'époque perse. En effet, l'hypothèse d'une implantation perse, associée à une politique achéménide portée par des représentants du pouvoir royal, a pendant un temps prévalu. Nous verrons qu'elle est largement remise en cause par l'étude de la documentation démotique mise au jour sur le site d'Ayn-Manâwîr, mais sans doute une approche renouvelée de la culture matérielle oasienne peut-elle permettre de contribuer au débat.

Même s'il n'est guère question d'affirmer avec G. Kossinna que « les aires de cultures archéologiques définies précisément correspondent sans discussion possible avec la nation de peuples ou de tribus particulières $\gg^{30}$ et qu' un ensemble cohérent d'artefacts archéologiques - une culture archéologique - est systématiquement le témoignage d'une ethnie homogène, l'identification de groupes culturels distincts, autonomes, qui éventuellement entrent en contact par le biais d'échanges, est une question que l'on est souvent amené à se poser, et à mettre en relation avec la problématique de l'ethnicité. En l'absence de corpus textuel suffisant, il est inévitable de chercher à identifier des contenus culturels constitutifs d'«identités ethniques» et de les intégrer dans une réflexion sur les dynamiques de l'interaction sociale. Autrement dit, pour identifier un «travail » au cœur du système, il faut nécessairement déterminer un bruit de fond, au sein duquel le travail produit une dissonance, ou du moins se distingue. La question qui s'est posée à nous a donc été celle-ci : comment interpréter, au sein du matériel archéologique livré par un site, un groupement d'artefacts apparemment « exogènes » et dans quelle mesure doivent-ils être considérés comme tels ? À partir de quelle quantité d'items peut-on considérer qu'on a affaire à un assemblage significatif, et significatif de quoi ? Cet assemblage implique-t-il a) la présence d'un groupe de population exogène (importation liée à l'installation d'un nouveau groupe) ?

\footnotetext{
$28 \quad$ Bousquet 1999.

29 Wuttmann, communication orale.

30 Kossinna 1911, 3.
} 
b) l'existence d'échanges économiques, n'impliquant pas nécessairement la présence d'une population exogène (importation liée à l'échange) ? Dans ces deux cas, on maintient l'idée qu'il y a deux groupes culturels distincts, qui soit se déplacent, soit font circuler des objets, et on reste dans une approche culture-historique : les changements, les éléments dirimants dans une culture archéologique sont associés soit à une migration, soit à un échange.

Toutefois, si on se place dans le cadre de définition posé en introduction, dans lequel l'ethnicité, bien plus qu'un caractère objectif, inné, est un phénomène qui relève d'une auto-désignation (self-ascription) d'un groupe ou d'un individu, on est amené à se demander ce que révèle, au sein d'une société donnée, la présence d'objets et de traits associés à une culture matérielle « exogène » ou d'influence exogène, a fortiori lorsque le contexte est celui d'une nécropole. Dans quelle mesure l'adoption de traits spécifiques ou d'objets spécifiques d'une culture matérielle exogène (par importation ou par imitation locale), en particulier dans le cadre funéraire, recouvre-t-elle une part d'affichage d'une appartenance ethnique par des individus, davantage que la présence d'individus venus de l'extérieur ou l'existence d'échanges de biens matériels avec d'autres groupes culturels? Que peut nous enseigner une telle revendication?

\section{Les secteurs d'époque perse des nécropoles d'El-Deir}

C'est en 1998 quel'équipe de Fr. Dunand a commencél'exploration des nécropoles $\mathrm{d}^{\prime} E l-D e i r^{31}$. Le site se trouve dans une vaste plaine, au pied de l'escarpement qui forme la limite nord-est de l'oasis, avec un dénivelé important de l'ordre de 300 mètres, et au débouché d'une des passes qui permettent de quitter l'oasis pour rejoindre la vallée du Nil, en direction de Girga et d'Abydos : le Naqb Abou Sighawal. La zone est actuellement désertique, ce qui a assuré une remarquable conservation du matériel archéologique. Tout autour de la forteresse romaine qui domine le site, disposés en arc de cercle, se trouvent les cinq secteurs de nécropoles mis au jour et fouillés : ils ont fonctionné successivement, depuis l'époque (saïto-)perse jusqu'à l'époque chrétienne ( $\mathrm{IV}^{\mathrm{e}}-\mathrm{V}^{\mathrm{e}}$ s. ap. J.-C. $)^{32}$.

L'étude du matériel des nécropoles a permis de proposer une chronologie de leur implantation. Une première phase est datable de l'époque perse, avec le secteur nord-est et une tombe isolée (T1) implantée à proximité du temple ; le secteur sud semble avoir commencé à fonctionner à l'époque (saïto-)perse et perduréà l'époque ptolémaïque, pour être réutilisé ponctuellement à l'époque romaine. Les secteurs nord et est présentent des

\footnotetext{
$31 \quad$ Fouilles menées dans le cadre de l'université de Strasbourg, UMR 7044.

32 Dunand \& Lichtenberg 2008, Dunand et al. 2010.
} 
caractéristiques de l'époque ptolémaïque et de l'époque romaine. Enfin, le secteur ouest a été clairement daté de l'époque chrétienne, avec une implantation au $\mathrm{IV}^{\mathrm{e}} \mathrm{s}$. ap. J.-C.

C'est aux secteurs et au matériel d'époque (saïto-)perse que je voudrais m'intéresser dans le cadre de cette contribution. En effet, leur interprétation s'articule avec la réflexion d'ensemble menée au sein de l'équipe sur la mise en valeur d'un terroir irrigué à El-Deir et sur l'implantation d'une population dans l'oasis à l'époque de la domination achéménide. De fait, trois groupes de tombes se distinguent très nettement du reste des nécropoles : le faciès d'une partie du matériel céramique et/ou le type même d'architecture des tombes semblent relever de périodes antérieures à l'époque ptolémaïque et présentent des traits culturels spécifiques. Il s'agit de la tombe isolée T1, des tombes du secteur nord-est et de celles du secteur sud.

1) La tombe isolée $T 1$ a été découverte en contrebas du temple, au sud-est. Elle est constituée d'un puits d'accès et d'un caveau. Le sol présente deux niveaux, le sarcophage en pierre étant encastré dans le sol au niveau inférieur et entouré d'une tranchée.

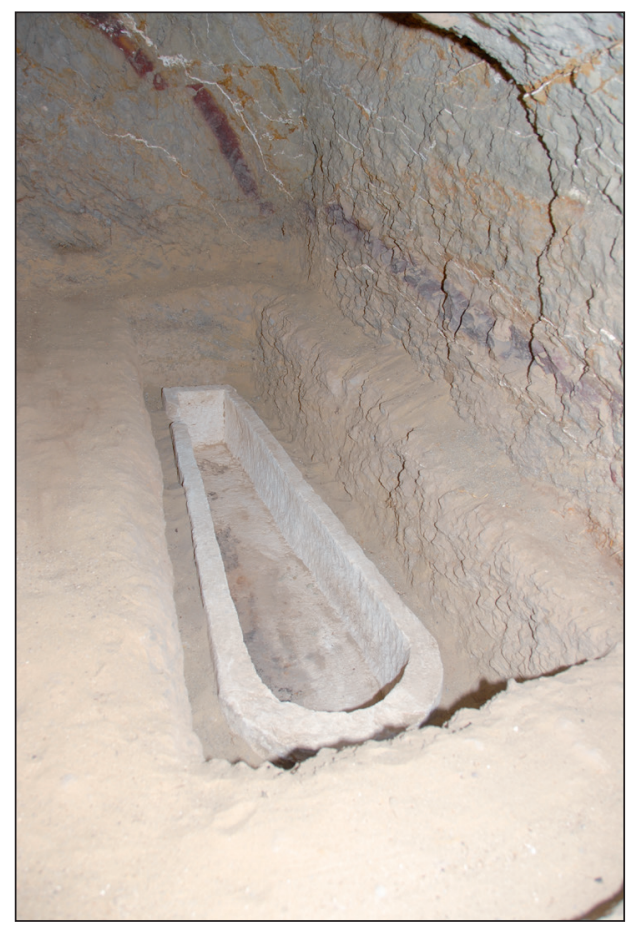

Fig. 2 : la tombe isolée T1. Cliché : R. Lichtenberg 
Ce type est tout à fait unique à El-Deir, et les rares parallèles rencontrés dans la Vallée du Nil et dans l'oasis sont datables de l'époque saïto-perse. À Saqqara, en effet, un groupe de trois tombes a été mis au jour par G. Maspéro et A. Barsanti devant la face sud de la pyramide d'Ounas ${ }^{33}$. Chaque tombeau se composait d'un grand et d'un petit puits communicants, le grand puits étant occupé tout entier par la cuve du sarcophage autour duquel on bâtissait la chambre dans un second temps. Le système du double puits permettait de descendre le lourd couvercle du sarcophage en le déposant sur du sable, qui était ensuite évacué par le petit puits. C'est là un trait caractéristique de tout un ensemble de tombes situées à Saqqara (notamment à Abousir $^{34}$ ) et à Héliopolis ${ }^{35}$ et que l'on date communément de l'époque saïto-perse. Il s'agit de grandes tombes à puits représentant un type très spécifique d'architecture funéraire, dont le développement est à peu près limité à la nécropole memphite pendant la XXVI ${ }^{e}$ dynastie. Aucune ne peut être datée avec assurance de la XXVII ${ }^{e}$ dynastie, mais on conserve cette désignation, car, parmi les tombes d'Abousir, celle du fameux dignitaire égyptien Oudjahorresnê, dont la collaboration avec le pouvoir achéménide a fait couler beaucoup d'encre, fut commencée sous Amasis, mais n'a pu être utilisée que sous Darius $\mathrm{I}^{\mathrm{e}{ }^{36}}$. L'une des trois tombes mentionnées précédemment, qui sont datées par G. Maspéro de la fin de la XXVI e dynastie et du début de la XXVII e dynastie (milieu du VI -début du V ${ }^{\mathrm{e}}$ s. av. J.-C.), était celle du médecin-chef Psammétique, qui était ornée d'inscriptions copiées des Textes des Pyramides.

\footnotetext{
33 Porter et al. 1974, 648-651; Barsanti 1901 ; Bresciani et al. 1977.

34 Lauer 1954 ; El-Sadeek 1984, 162-164; El-Aguizy 2010.

35 Gauthier 1933 ; Bickel \& Tallet 1997 ; El-Sadeek 1984, ibid.

36 Bares 1999 ; Verner 1989 ; Verner 2002, chap. VIII. Voir également, pour Oudjahorresnê : Chevereau 1985, 101102.
} 


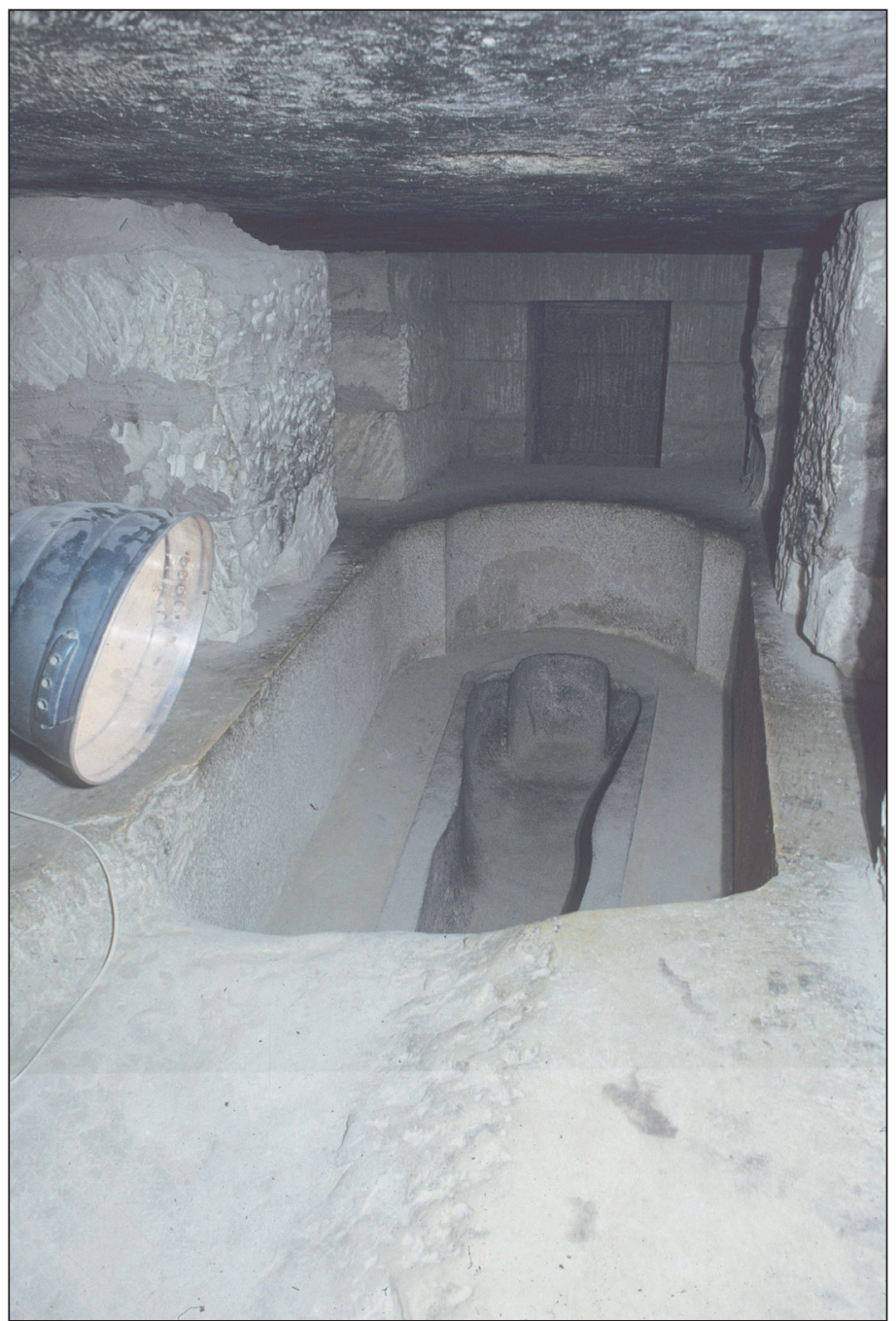

Fig. 3 : la tombe du médecin-chef Psammétique à Saqqara. Cliché : R. Lichtenberg

Comme à El-Deir, le sarcophage, en calcaire, était engagé dans le sol. À Kharga, dans la nécropole du temple saïto-perse d'Hibis, fouillée par H.E. Winlock mais non publiée, ce type de tombe est également attesté. 

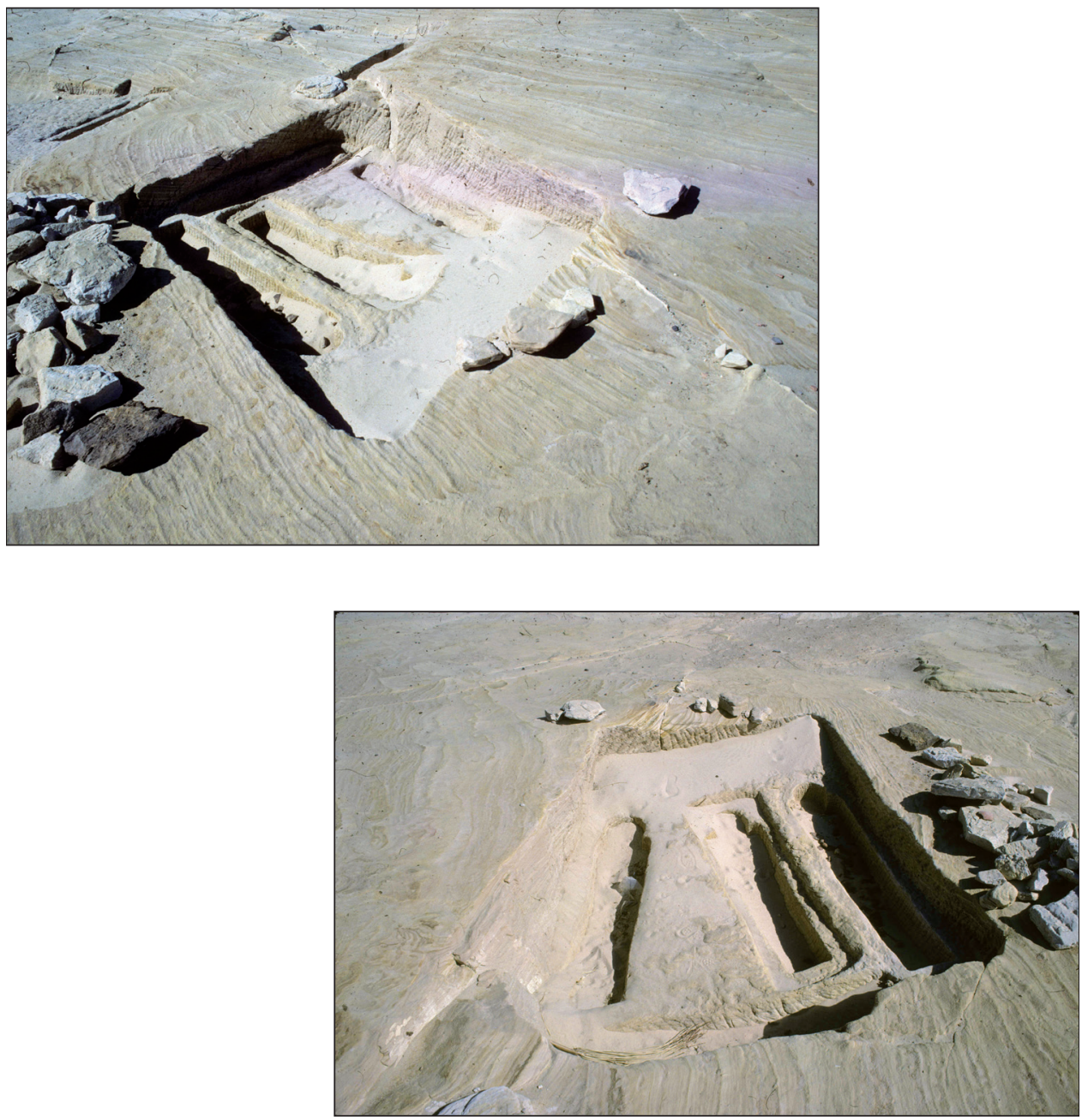

Fig. 4a-b : tombes d'époque saïto-perse dans la nécropole d'Hibis (oasis de Kharga). Clichés : Fr. Dunand (a) et R. Lichtenberg (b)

Malheureusement, aucun matériel n'a été mis au jour dans la tombe isolée d'El-Deir, à l'exception d'une amulette en forme d'œil-oudjat et d'une perle de fä̈ence. 
2) Le secteur nord-est présente une relative homogénéité du matériel.

Il se compose de trois groupes de deux tombes jumelles, orientées nord/sud pour les tombes NE1-NE2 et NE3-NE4 et nord-ouest/sud-ouest pour les tombes NE5-NE6. Elles sont établies au flanc d'une petite colline, au nord de la forteresse.

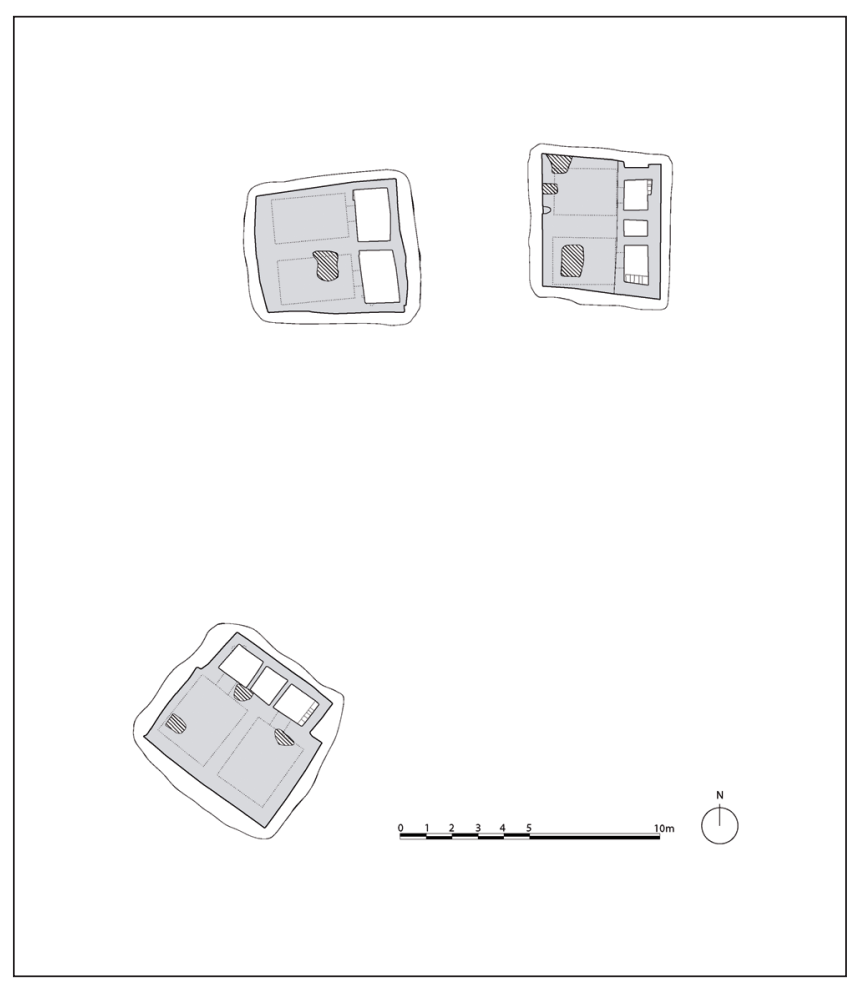

Fig. 5 : le secteur nord-est (E. Devaux)

Une de leurs caractéristiques est l'absence de structure visible au-dessus du niveau du sol. Il s'agit de tombes en brique à caveaux voûtés (voûtes nubiennes à arceaux obliques), construites dans de vastes fosses. On accède à chaque caveau par un puits creusé à environ 1,5 mètre de profondeur. Les parois des caveaux et des puits sont enduites de mouna (enduit de jointage). Des marches en brique ou des encoches creusées dans les parois permettent l'accès au fond du puits sur lequel ouvre le caveau. L'ouverture de ce dernier, cintrée, était généralement fermée par des briques recouvertes de mouna. Des sarcophages en calcaire ont été mis au jour dans les tombes. 


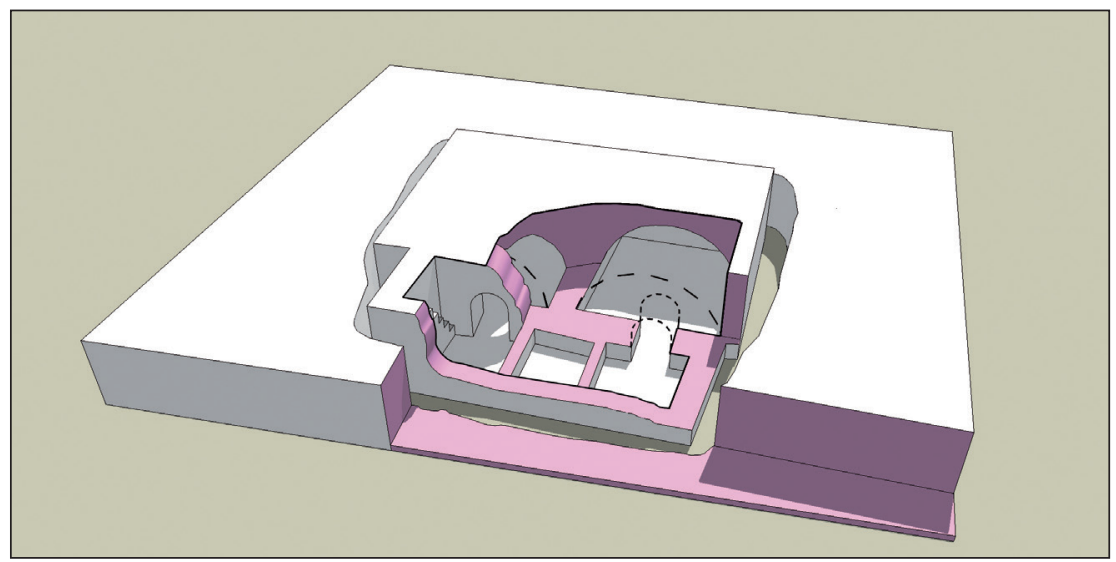

Fig. 6 : un groupe de tombes du secteur nord-est, restitution en trois dimensions (E. Devaux)

Ces tombes parallélépipédiques, enterrées dans une fosse, sont là encore tout à fait différentes de ce qui a pu être observé dans le reste de la nécropole d'El-Deir et dans l'oasis. Des parallèles sont toutefois observables dans l'oasis de Dakhlah, sur les sites de Tell Marqula ${ }^{37}$, et de Bir Talata el-Arab ${ }^{38}$, et datables de l'époque perse.

Le matériel céramique, étudié par $\mathrm{S}$. Brones, présente un faciès bien attesté dans l'oasis de Kharga, en particulier dans l'implantation d'époque perse d'Ayn-Manâwîr. Les formes listées ci-dessous, très courantes à Ayn-Manâwîr, furent produites dans l'oasis de Kharga à partir de la XXVII e dynastie jusqu'à la XXX ${ }^{\mathrm{e}}$ dynastie ${ }^{39}$ : il s'agit d'une série de six sigas dont plusieurs à col haut, d'une série de gobelets, de deux jarres à panse ovoïde et d'une gourde. Vient s'ajouter une forme plus rare, un vase Bès. La datation d'époque (saïto-)perse de ce secteur de la nécropole repose donc grandement sur l'identification du faciès céramique - la distinction entre le matériel d'époque saïte et le matériel d'époque perse restant toutefois difficile à faire. Les notices suivantes ont été rédigées grâce aux informations communiquées par $\mathrm{S}$. Brones ${ }^{40}$.

\footnotetext{
37 Communication personnelle de P. Davoli. Aucun relevé ni publication de ces tombes ne sont disponibles à ce jour.

38 Communication personnelle d'O. E. Kaper. Une publication est attendue prochainement, dans le volume des Oasis Papers IV-V, édité par O. E. Kaper et F. Leemhuis.

39 C'est la phase 1 et 2 de la chronologie relative d'Ayn-Manâwîr, à partir du V $\mathrm{V}^{\mathrm{e}}$ s. av. J.-C., époque perse et post-perse : Wuttmann et al. 1998, 441-442 (contribution de S. Marchand).

40 Dunand et al. 2013.
} 
a. Vase Bès (ED NE.5.05)

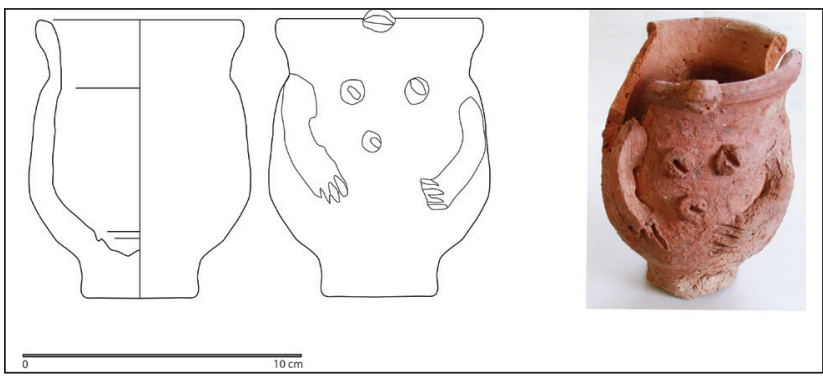

Fig. 7 : cliché et dessin Sophie Brones

Provenance : tombe S5.

Petit pot à pied et à panse ovoïde.

Ouverture large, col évasé et lèvre simple.

Diamètre : $7,5 \mathrm{~cm}$; hauteur : $9 \mathrm{~cm}$.

Éléments figuratifs (yeux, nez et bras du dieu Bès) appliqués sur la lèvre et la panse. Les éléments de reliefs ont été appliqués à la main de manière assez maladroite (nombreuses traces de doigts présentes en surface), ce qui donne à l'engobe un aspect rugueux.

Pâte locale, moyennement fine, poreuse, de couleur orangée, couverte d'un engobe rose/rouge.

Ce vase et ses éléments de reliefs appliqués rappellent les vases Bès dont un exemplaire d'importation a été exhumé dans la nécropole sud (cf. infra), et a été daté du début du IVe s. av. J.-C. Selon S. Brones, ED NE.5.05 pourrait être une copie locale de ce vase d'importation, et sa datation est sans doute contemporaine, voire légèrement postérieure (peut-être de la fin du IVe-début du III' ${ }^{\mathrm{e}}$ s. av. J.-C., selon C. Defernez) ${ }^{41}$.

b. Série de gobelets (ED NE.2.06, ED NE.2.07 et fragments)

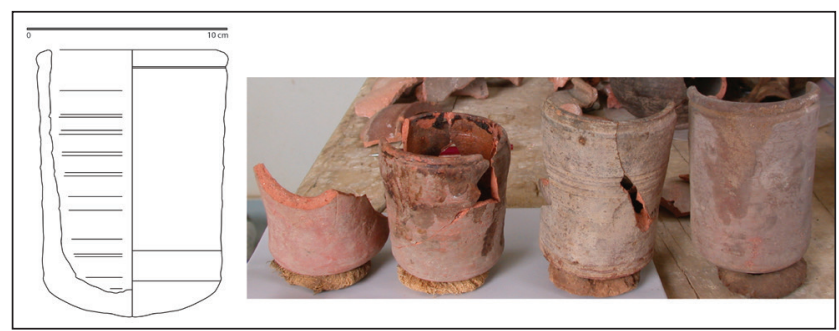

Fig. 8 : photographie et dessin Sophie Brones

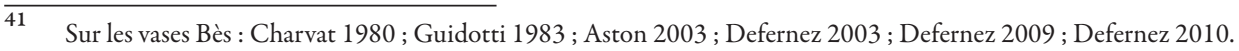


Provenance : tombe NE.2, avec en outre deux fragments provenant de la tombe NE.1.

Fond arrondi à léger ombilic, panse rectiligne très légèrement évasée vers le haut, lèvre arrondie simple marquée par un léger bourrelet que dessine une strie sous le col.

Pâte locale de couleur rosée, couverte d'un engobe rouge-brun.

La forme est par ailleurs inédite sur le site. L'exemplaire présenté ici est le plus grand.

Diamètre maximal : $9,5 \mathrm{~cm}$; hauteur : $13,5 \mathrm{~cm}$.

Des dépôts trouvés à l'intérieur des autres exemplaires de la série n'ont pas été analysés, il pourrait toutefois s'agir de résines ayant servi à la momification. On note de nombreuses traces de doigts et empreintes digitales sur l'un des exemplaires.

Forme attestée à 'Ayn-Manâwîr de la XXVII' à la XXX' dynastie ${ }^{42}$.

\section{c. Sigas (ED NE.1.01 et ED NE.4.01)}
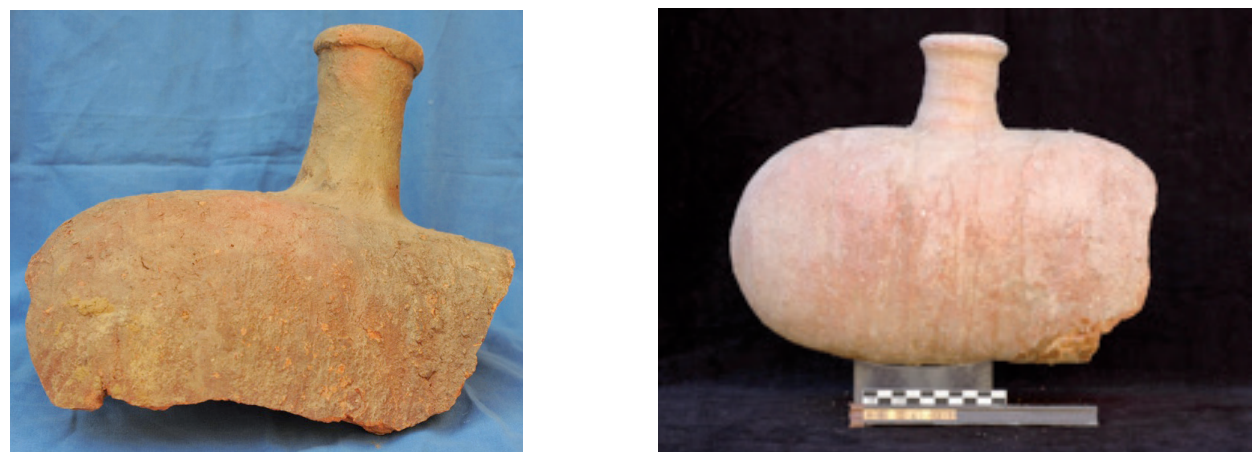

Fig. 9a-b : photographies R. Lichtenberg

Provenance : tombes NE.1 et NE.4.

Il s'agit là d'une forme de conteneur oblong typique des oasis de Kharga, Dakhla et Baharyia, en forme d'obus ou de barattes ${ }^{43}$.

La siga ED NE.1.01 est de petites dimensions, avec une hauteur de col $(4 \mathrm{~cm}$ environ) très importante pour ce type. Le corps en forme de baril, avec les extrémités arrondies, atteste qu'il s'agit d'un exemplaire remontant probablement à la Basse Époque. L'exemplaire est similaire à ceux que l'on trouve à 'Ayn-Manâwîr, à partir de la XXVII dynastie jusqu'à la $\mathrm{XXX}^{\mathrm{e}}$ dynastie.

Pâte locale orangée, engobe rouge brun.

\footnotetext{
$42 \quad$ Marchand 1997, 45-46.

43 Hope et al. 2000 ; Marchand 2000; Marchand 2007, 491-492.
} 
Il en va de même pour la siga ED NE.4.01, pour laquelle des parallèles sont également attestés à 'Ayn-Manâwîr ${ }^{44}$.

d. Deux jarres à panse ovoïde (ED NE.1-2.1 et ED NE.5-6.01)

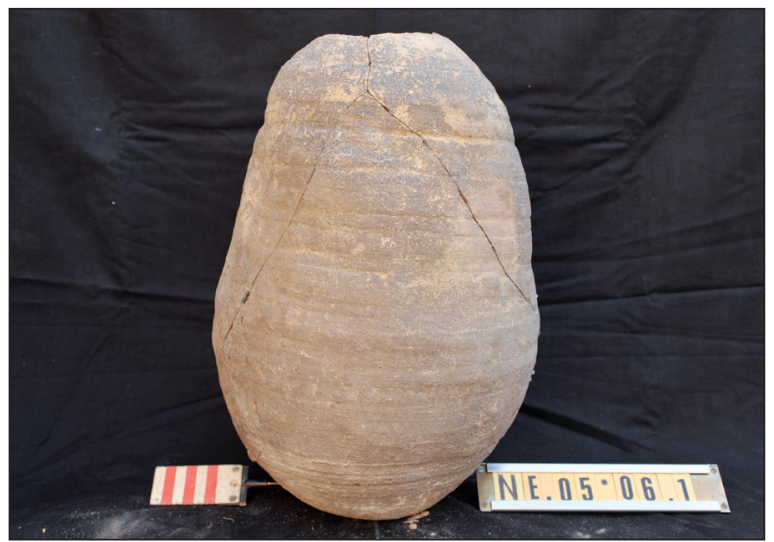

Fig. 10 : photographie R. Lichtenberg

Provenance : tombes NE.1 et NE.5.

Panses de jarres de grande taille.

Argile locale grossière.

Forme attestée à 'Ayn-Manâwîr de la XXVII à la XXX' dynastie ${ }^{45}$.

e. Une gourde (NE.2.05)

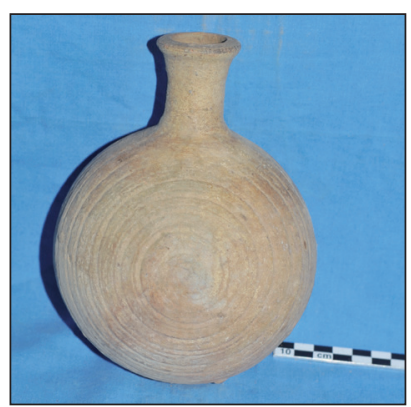

Fig. 11 : photographie R. Lichtenberg

44 Marchand 1996, 425-426, fig. 50 (groupe 14); Marchand 1997, 46 et fig. 3 ; Marchand 2007, 492, fig. 15.

45 Marchand 2007, 492, fig. 18. 
Provenance : tombe NE.2.

Gourde à col haut et au goulot légèrement évasé, lèvre horizontale, corps arrondi de forme régulière, stries de tournage marquées.

Pâte locale moyennement fine, nombreuses traces d'inclusions végétales visibles à l'œil nu, surface lissée beige rosée.

Forme attestée à 'Ayn-Manâwîr de la XXVII à la XXX" dynastie ${ }^{46}$.

3) Enfin, le secteur sud a livré du matériel d'époque saïto-perse et ptolémaïque, et présente des traces de réemploi à l'époque romaine. On y trouve des momies relevant de techniques très différentes dans la même tombe, voire dans le même caveau ${ }^{47}$.

Cette nécropole est implantée sur une petite élévation de terrain (d'environ 1,5 mètre de hauteur maximale), de forme grossièrement ovale, longue d'environ 70 mètres, orientée nord-sud, à 200 mètres au sud-ouest de la forteresse. Les tombes ont été distribuées de façon irrégulière. Huit tombes ont été identifiées : six d'entre elles sont des tombes à puits comportant de deux à quatre caveaux, creusées en profondeur dans l'élévation de terrain; deux autres, sur le flanc est, sont des tombes à un seul caveau précédé d'un petit puits, creusées à faible profondeur (S3 et S4). Les ouvertures des caveaux, de dimensions limitées, étaient obturées par des dalles en calcaire dont on a retrouvé quelques rares exemplaires. Si on n'a pas trouvé de sarcophage en pierre dans ce secteur, des sarcophages en bois plus ou moins décorés ont été découverts dans plusieurs tombes ${ }^{48}$. On constate en outre une forte homogénéité stylistique des masques funéraires qui ornaient ces sarcophages avec ceux mis au jour dans la nécropole nord-est ${ }^{49}$.

Des boîtes à Osiris ont été découvertes dans deux des tombes : elles correspondent à un usage qui remonte au moins à la $\mathrm{XXV}^{\mathrm{e}}$ dynastie, très répandu à Basse Époque et qui semble bien avoir disparu dès avant l'époque romaine ${ }^{50}$.

Mais c'est surtout le matériel céramologique (vase Bès, bol de tradition orientale dit « achéménide », cruches à bec verseur, siga) qui indique une datation haute, d'après S. Brones ${ }^{51}$ :

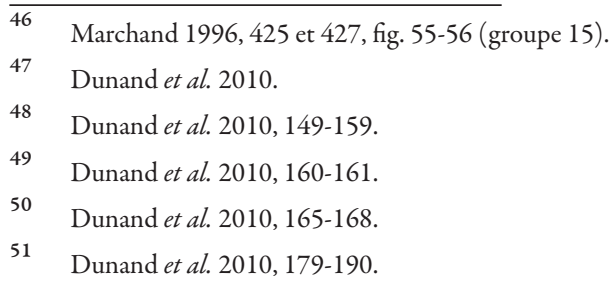


a. Vase Bès (ED S.5.2.2) ${ }^{52}$
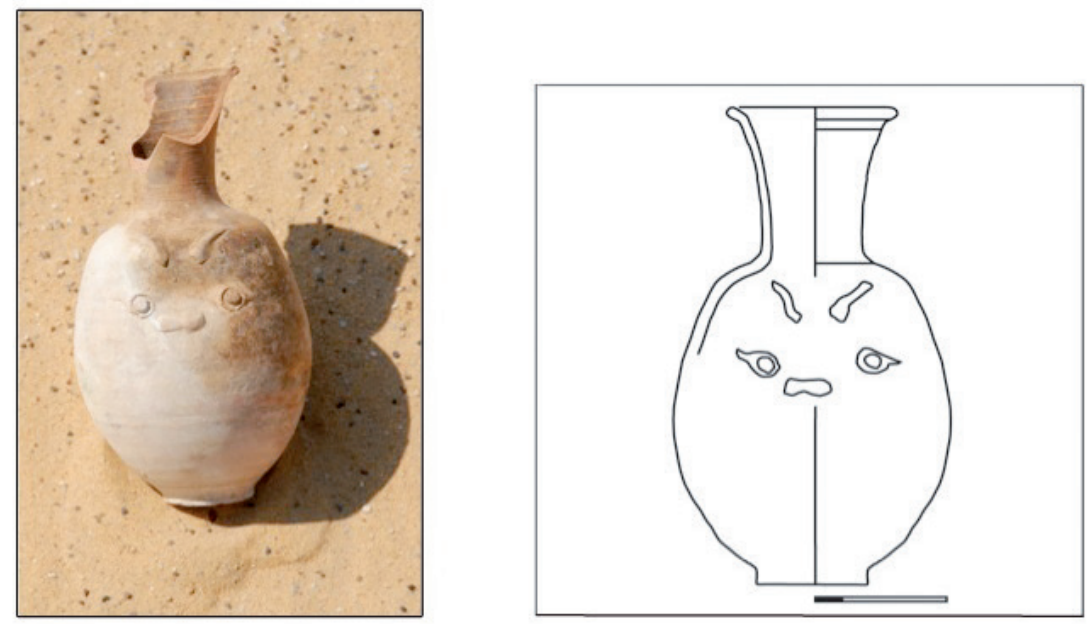

Fig. 12 : photographie et dessin Sophie Brones

Provenance : tombe S.5, caveau 2.

Vase à panse ovoïde et à col haut et évasé, avec un rebord simple évasé. Pied annulaire peu dégagé du fond.

Décor appliqué (yeux, nez, sourcils du dieu Bès) sur le haut de la panse.

Surface légèrement enfoncée à l'endroit du décor, probablement du fait d'un défaut de cuisson.

Pâte calcaire fine de couleur rose orangé, non locale (importation de la Vallée du Nil). Engobe beige clair.

Une datation de l'époque perse sur la base de parallèles observés à Saqqara, antérieurs à la $\mathrm{XXX}^{\mathrm{e}}$ dynastie ${ }^{53}$, a été proposée par S. Brones, et confirmée par les travaux de C. Defernez sur les vases Bès : cet exemplaire se place entre les types I et J du tableau élaboré par C. Defernez, correspondant aux phases $\mathrm{Va}$ (fin du $\mathrm{V}^{\mathrm{e}}-1^{\mathrm{er}}$ quart du IV e av. J.-C.) et IVa ( $2^{\text {e }}$ quart du IV e s. av. J.-C. $)^{54}$. Elle se prononce en faveur de la première moitié du IVe $\mathrm{s}$. av. J.-C. ${ }^{55}$

\footnotetext{
52 Dunand et al. 2010, 188.

53 Lecuyot 2000, 241, BE 15. Selon lui, une datation est possible du V es. av. J.-C. (types V et VI de Aston).

54 Defernez 2010, repris dans Defernez 2011.

55 Communication personnelle.
} 
b. Bol de tradition orientale, dit « achéménide » $(E D \text { S.6.4.1 })^{56}$

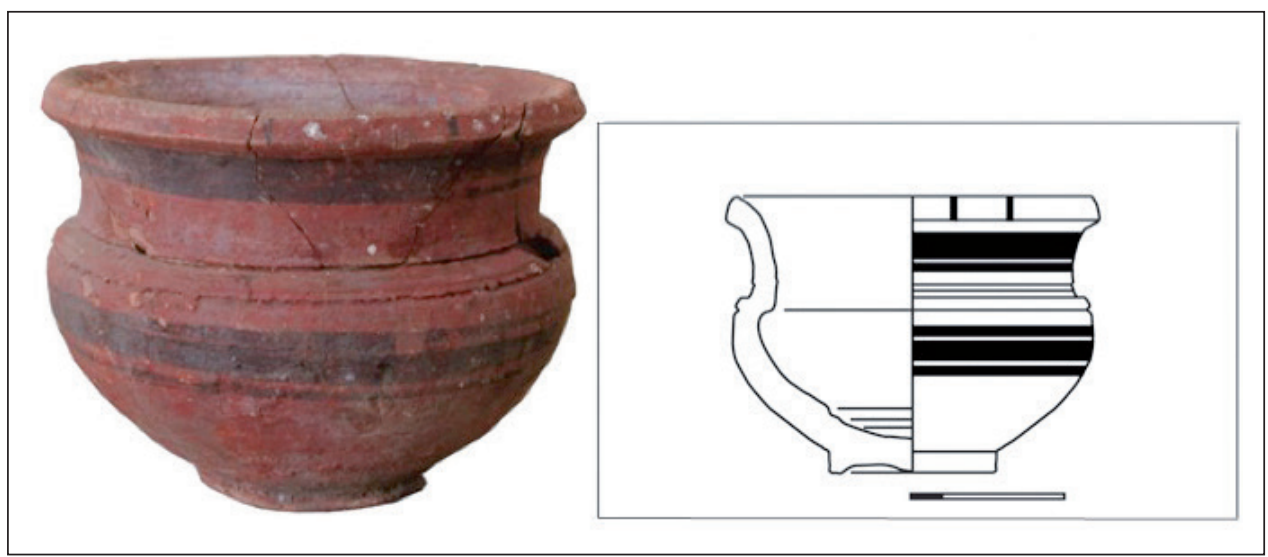

Fig. 13 : photographie et dessin Sophie Brones

Provenance : Tombe S.6, caveau 4.

Grand bol à épaule carénée et au bord rubané et évasé, à pied annulaire peu dégagé du fond.

Pâte fine, parois épaisses couvertes d'un engobe rouge, décor de bandes linéaires noires sur le col et le haut de la panse. Guillochis très fins peints en noir sur le bord.

Parallèles à 'Ayn-Manâwîr datés du IVe s. av. J.-C. (avec un engobe blanc) ${ }^{57}$. La forme est également attestée à Héracléion ${ }^{58}$, à Tell el-Herr ${ }^{59}$, dans la nécropole thébaine ${ }^{60}$ et à Boûto ${ }^{61}$.

Un exemplaire en métal de la même époque est conservé à Naples (Musée Archéologique, $\left.\mathrm{n}^{\circ} 17.19\right)$. Son décor de bandes linéaires noires et sa forme générale, avec une base annulaire, permettent de le situer au IVe $s$. av. J.-C. ou au tout début de l'époque hellénistique.

\footnotetext{
$56 \quad$ Dunand et al. 2010, 187.

57 Marchand 1996, 417-18, fig. 15 et 16 (groupe 1) ; Marchand 1997, 48, fig. 2 (variante avec bandes peintes).

58 Grataloup et al. 2006, 233, cat. n412.

59 Defernez 2003, 330 et pl. LXXII, n²08.

60 Defernez 2010, 117-118.

61 Defernez 2003, 1, 137 (d'après une communication personnelle de P. French).
} 
c. Cruches à bec verseur (ED S6.4.2) ${ }^{62}$

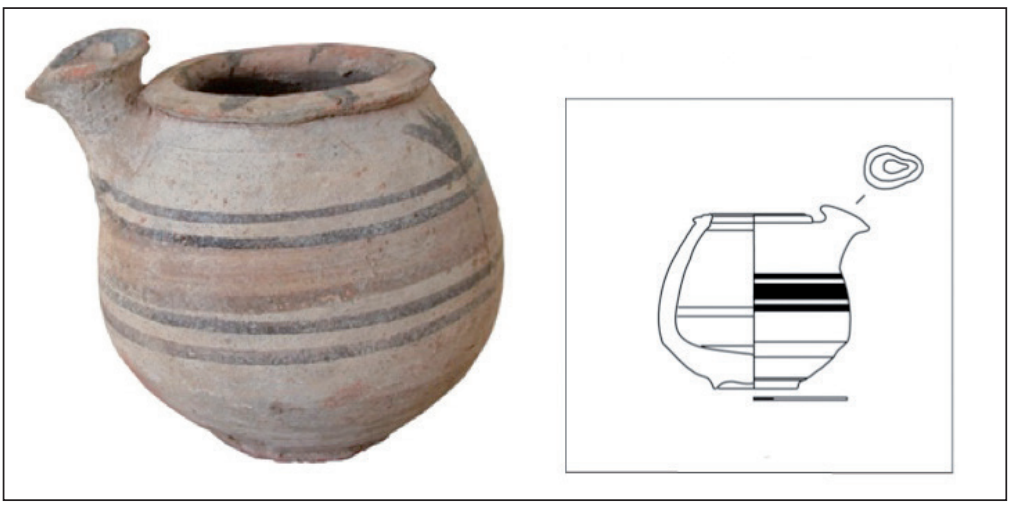

Fig. 14 : photographie et dessin Sophie Brones

Provenance : tombe S.6, caveau 4.

Deux petites cruches à bec trilobé, variante d'une forme de guttus grec, dépourvue d'anse, avec une panse piriforme.

Pâte moyennement fine couverte d'un engobe clair et décor de bandes noires à mi-hauteur de la panse (variante : décor de fleur de lotus sur le col).

Parallèles à Ayn-Manâwîr, à partir des XXVIII ${ }^{e}-X_{X X}$ dynasties $^{63}$. On peut se prononcer en faveur d'une datation aux IV $\mathrm{IV}^{\mathrm{I}} \mathrm{III} \mathrm{e}^{\mathrm{e}}$ s. av. J.-C. selon C. Defernez. Toutefois, des parallèles sont attestés dans l'oasis de Dakhla, qui sont datables de l'époque romaine ${ }^{64}$.

d. Siga $(S 4.0 .1)^{65}$

Siga de taille moyenne à col haut et légèrement évasé, rebord arrondi et épaissi.

Pâte moyennement fine, grise en cassure et rose rouge à l'extérieur, engobe beige.

Parallèle des XXVII ${ }^{e}-X_{X X}$ dynasties attesté à Ayn-Manâwîr (décoré) ${ }^{66}$.

Le matériel exhumé dans les nécropoles d'El-Deir n'est jamais antérieur à l'époque saïte et milite donc en faveur d'une réimplantation à El-Deir à l'époque saïtoperse, après une longue phase d'abandon depuis l'épipaléolithique ou le paléolithique,

\footnotetext{
62 Dunand et al. 2010, 186.

63 Marchand 1996, 422-424, fig. 43-44; Marchand 1997, fig. 1.

64 Hope et al. 2000, pl. XXIV.

65 Dunand et al. 2010, 185.

66 Marchand 2000, fig. 6.
} 
mais il est très probable que l'implantation à El-Deir ait été plus précoce qu'au sud de l'oasis ${ }^{67}$. Cela concorde donc avec la solution de continuité relevée plus haut, entre la fin de l'Ancien Empire et le Ve siècle av. J.-C., à 'Ayn-Manâwîr. En outre, la fouille d'un édifice découvert entre le temple et la forteresse a livré un lot d'ostraca, dont deux appartiennent selon $\mathrm{M}$. Chauveau à la phase du démotique ancien (VIe-IVe s. av. J.-C.), celle qui a justement fourni l'apport documentaire le plus important d'Ayn-Manâwîr. La fonction de cet édifice est pour l'heure mal cernée, mais il y aura certainement lieu de le mettre en relation avec l'exploitation des ressources en eau à El-Deir, car il se trouve sur une butte rocheuse, à proximité de la zone d'artésianisme qui alimente l'ensemble du système d'irrigation du site. C'est à notre sens dans le contexte global de la recolonisation de l'oasis à l'époque perse qu' il faut comprendre l'implantation d'une population et de ses nécropoles à El-Deir.

\section{Transposition et imitation locale :} la question du « style international achéménide »

Que dire, à partir du matériel des nécropoles, de cette population ? Si j'ai souligné jusqu'alors l'existence d'éléments saillants, dirimants, dans le matériel d'ElDeir, il convient de noter l'importance des éléments de continuité avec le reste du matériel funéraire mis au jour dans les secteurs d'époque ptolémaïque et romaine, tant à El-Deir que dans les nécropoles d'Ayn el-Labakha, Dabasheyia ou Douch pour les mêmes époques. Dans tous les cas, les traditions funéraires égyptiennes sont dominantes : l'usage des sarcophages, de bois ou de pierre, est généralisé - une trentaine a été inhumée dans la nécropole sud, avec des éléments de masques; il en va de même au nord-est. S'il est maladroit, le style d' un couvercle de sarcophage orné de la déesse du ciel Nout provenant de la nécropole sud (ED S2.1.2), évoque des croyances funéraires égyptiennes bien connues, liées à la régénération du défunt; son nom est même inscrit en hiéroglyphes dans le disque solaire qui orne sa tête.

\footnotetext{
$67 \quad$ La prospection menée par J.-P. Bravard, A. Mostafa et R. Garcier en 2009 et 2010 a permis de mettre au jour une grande spécificité d'El-Deir au sein de l'oasis, qui est liée à un artésianisme extrêmement vigoureux : Tallet et al. 2011 ; Tallet et al. 2012.
} 


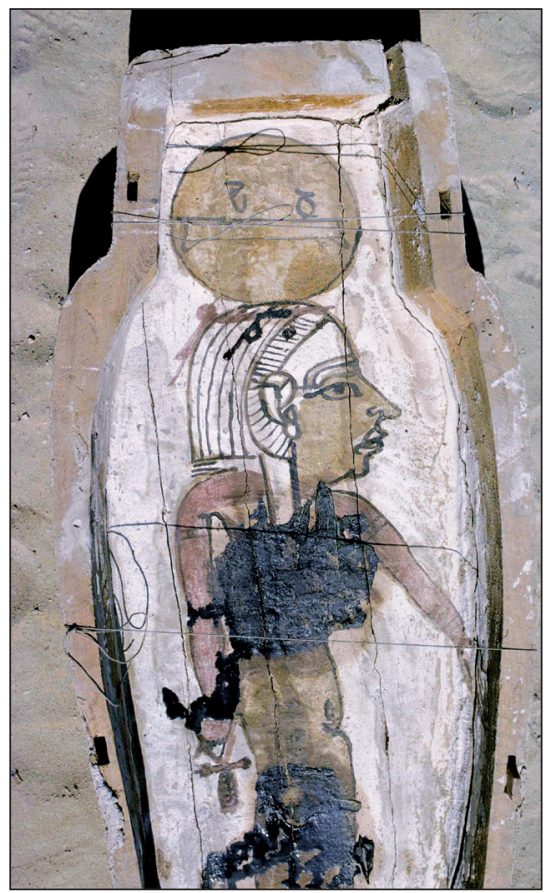

Fig. 15 : couvercle de sarcophage orné de la déesse du ciel Nout provenant de la nécropole sud

Dans les deux secteurs sud et nord-est, sur le plan des idées et des croyances funéraires, ainsi que pour beaucoup de formes céramiques, on n'a donc pas le sentiment d'une rupture culturelle par rapport au reste du matériel funéraire oasien ou provenant de la Vallée. L'hypothèse de l'implantation d'un groupe culturel exogène nous semble à écarter.

Reste à interpréter la présence d'éléments dirimants, qui témoignent à mon sens d'un «travail» au sein de la société d'El-Deir. En effet, C. Defernez a récemment démontré, dans un article portant sur le matériel céramologique du site de Tell el-Herr (Nord-Sinaï), qu'il existait des imitations locales, en terre cuite, de vaisselle métallique de tradition achéménide ${ }^{68}$. Elle analyse quatre vases Bès se démarquant du répertoire égyptien par leur décor et leur profil atypique, datés entre le milieu du $\mathrm{V}^{\mathrm{e}}$ s. et le premier quart du $\mathrm{IV}^{\mathrm{e}} \mathrm{s}$. av. J.-C., et rappelle l'essor que connut le dieu Bès dans l'Empire

\footnotetext{
68 Defernez 2010 ; voir aussi Marchand 2011.
} 
achéménide (des effigies ont été découvertes dans plusieurs satrapies de l'Empire). Elle a identifié une série de formes attestées dans le matériel céramologique du Sinaï et du Delta à l'époque de la domination perse, qu'elle interprète comme des répliques ou éventuellement des adaptations moins onéreuses de prototypes de métal ou parfois de vaisselle fine, luxueux ou semi-luxueux. Les artisans potiers auraient ainsi transféré certains éléments formels de la vaisselle métallique ou de pierre sur la vaisselle en terre cuite, alors même que la vaisselle proprement métallique se développait, à l'intention des élites friandes d'objets de prestige. Ces vases ne s'insèrent pas dans un répertoire égyptien connu et sont relativement rares. Les artefacts d'El-Deir ne sont certes pas de la qualité de ceux de Tell el-Herr mais on peut s'interroger sur leur relation possible avec ce qu' on a appelé le «style international achéménide ${ }^{69}$ :

a. Les vases Bès d'époque perse attestés dans les nécropoles sud et nord-est sont des unica dans les nécropoles d'El-Deir. Si le vase ED NE.5.05, très schématique, peut difficilement être rapproché de formes métalliques, le vase ED S.5.2.2, dont il est peutêtre une imitation, peut participer, selon C. Defernez, d'une forme de cruche ou de pichet bien proche de répliques en métal ${ }^{70}$.

b. Les jarres à panse de forme ovoïde présentent également des points de comparaison. Outre la finesse d'exécution du visage de Bès, le type A de vase Bès déterminé par C. Defernez à Tell el-Herr est caractérisé par sa panse ovoïde ${ }^{71}$, qu' elle rapproche d'un autre récipient, sans motif décoratif, mis au jour à Tell el-Herr ${ }^{72}$. La forme est attestée également à Tell el-Yahoudiyah, Souwa et Saft-Goshen ${ }^{73}$. Ce type de récipient de forme ovoïde est rare dans les systèmes de classement égyptien, et C. Defernez a établi des analogies avec des vaisselles de métal, tel un vase-situle en argent découvert dans la tombe III du tumulus de Zelenskoi, dans la région nord-pontique (daté du dernier quart du IVe s. av. J.-C.). Des parallèles peuvent également être notés avec d'autres vases-situle en argent provenant d'Égypte, mais datés d'époque ptolémaïque (cachette de Dendéra $)^{74}$.

c. Elle rapproche un troisième type de forme rare dans le répertoire égyptien, le gobelet cylindrique, de modèles de vaisselle métallique (bronze) mis au jour dans la

\footnotetext{
69 Melikian-Chirvani 1993; Defernez 2010.

70 Communication personnelle. Voir Defernez 2009.

71 Defernez 2010, fig. 1.

72 Defernez 2010, fig. 5, avec une variante : la base est arrondie.

73 Defernez 2010, 113.

74 Defernez 2010, 113-114.
} 
nécropole achéménide de Deve Hüyük, en Syrie du Nord, aménagée dans la première partie du $\mathrm{V}^{\mathrm{e}}$ siècle $^{75}$. Des gobelets en argile cylindriques ont par ailleurs été mis au jour dans le Delta égyptien et à Saqqara, ainsi que des gobelets de bronze sur le site de Thonis-Hérakleion, d'époque ptolémaïque ou peut-être antérieure ${ }^{76}$. L'un des vases Bès de Tell el-Herr reprend cette forme, tout comme la série des gobelets de la nécropole nord-est d'El-Deir.

d. Enfin, le petit bol à carène mis au jour dans la nécropole sud a été interprété par P. Ballet comme une transposition en céramique d'une forme de bol là encore attestée dans l'orfèvrerie achéménide, interprétation confirmée par C. Defernez ${ }^{77}$. Ce fut également la première interprétation de $S$. Marchand au sujet des vases à épaule carénée mis au jour à 'Ayn-Manâwîr, même si elle préfere faire montre de davantage de prudence aujourd'hui, en soulignant que cette forme a existé un peu avant la XXVII ${ }^{\mathrm{e}}$ dynastie et a perduré ensuite, jusqu'à l'époque ptolémaïque (fin du III ${ }^{\mathrm{e}}$ s. av. J.-C. ${ }^{78}$. Des bols de métal de ce type, d'époque perse, ont été mis au jour à Thèbes ${ }^{79}$, à Tell el-Maskhouta ${ }^{80}$ et à Thmouis ${ }^{81}$, comparables à ceux qu'on a pu découvrir dans le Levant ${ }^{82}$. Ces formes sont également connues en faïence et en verre ${ }^{83}$.

\section{Identité exhibée et stratégie de distinction sociale dans les nécropoles d'El-Deir ?*}

Il semblerait difficile d'affirmer qu'on a affaire à El-Deir à l'époque perse à un apport de population exogène, immigrée de Perse ou d'une autre région de l'Empire. Les groupes qui s'implantent sur le site semblent bien plutôt égyptiens, comme incite à le penser le matériel mis au jour dans les nécropoles : sans solution de continuité de l'époque perse à l'époque romaine, il présente dans l'ensemble des traits semblables à ce qui se rencontre dans le répertoire de la Vallée du Nil et dans les oasis pour l'ensemble

\footnotetext{
75 Defernez 2010, figs. 6-8.

76 Defernez 2010, 114-117.

77 Communications personnelles. Voir également Defernez 2003, 1, 137-138.

78 Marchand 1996, 417-418. Elle préfère parler de bols « de tradition orientale », sans les corréler exclusivement à l'époque perse. Voir également Defernez 2010, 117-118.

79 Cooney 1965, 40-42, pl. XXIII.

80 Rabinowitz 1956, 1-9, pls. IV et V.

81 Fossing 1937, 122.

82 Stern 1982, 145, fig. 238.

83 Stern \& Schlick-Nolte 1994, 166.
} 
de cette période. Dans l'abondante documentation textuelle d'Ayn-Manâwîr, étudiée par M. Chauveau et D. Agut-Labordère, et qui apporte beaucoup d'informations sur l'exploitation du système d'irrigation du site à l'époque perse, on est frappé par l'absence de représentants du pouvoir perse ; les acteurs de l'exploitation et de la gestion de l'eau, à tous les niveaux, sont des Égyptiens ${ }^{84}$. La documentation démotique d'El-Deir est malheureusement insuffisante pour cette période pour que nous puissions en tirer parti.

Le matériel dirimant au sein du corpus céramologique peut en revanche être pensé dans le cadre d'une stratégie de distinction sociale, politique et économique de certains habitants d'El-Deir par rapport au groupe culturel environnant. Le choix de la forme des tombes, l'usage d'une vaisselle d'imitation, peuvent relever d'une volonté d'affirmation d'une proximité avec l'administration perse : le cas d'Oudjahorresnê, souvent présenté comme un traitre ou un collaborateur, n'était sans doute pas isole ${ }^{85}$. Il convient toutefois de rester prudent dans l'interprétation de ce type d'objets de prestige. Par exemple, que dire du choix d'un vase Bès «persisant » importé de la Vallée ? Certes, il semble bien s'agir ici d'un objet de prestige, relevant d'une stratégie de distinction. Mais cette distinction se veut-elle ethnique ? Le prestige de l'objet provient-il du fait qu'il imite des formes achéménides ou tout simplement du fait qu'il est importé de la Vallée ? À Douch, des vases en faïence bleue mis au jour dans les nécropoles, importés de Memphis, relevaient, semble-t-il, d'une telle démarche ${ }^{86}$.

Il importe de se reporter au contexte de la mise en valeur de l'oasis à l'époque perse. Comme ce fut le cas avec le projet de Ptolémée II et de ses successeurs dans le Fayoum, l'Égypte a pu apparaître aux yeux des Grands Rois comme un grenier de l'Empire achéménide, un réservoir de ressources agricoles à exploiter. La politique économique perse, telle qu' elle transparaît à travers le Décret de Cambyse ${ }^{87}$ ou la réouverture du canal de Nechao II vers la mer Rouge sous le règne de Darius, est tournée vers l'accroissement de la productivité de la satrapie ${ }^{88}$. C'est ce contexte qui a permis à l'oasis de Kharga de recevoir un important peuplement égyptien à l'époque perse.

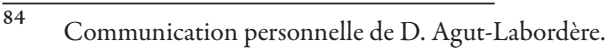

85 Briant 1996, 497-499 et 974-75; Menu 1998; Bares 1999, 31-43. Pendant les deux dominations perses, des dignitaires égyptiens sont attestés dans l'administration, dont probablement le fils aîné de Nectanébo II : Spalinger 1978, 153-154 ; Lichtheim 1973-1980, III, 41-44 ; Holm-Rasmussen 1988 ; Wessetzki 1991.

86 Dunand et al. 1992, 240.

$87 \quad$ P. BN $215, \mathrm{III}^{\mathrm{e}}$ s. av. J.-C.

88 Briant 1996, 493-494; Agut-Labordère 2005a ; Agut-Labordère 2005b.
} 
Un éclairage peut être apporté ici par la relecture du fameux texte de Polybe sur les qanâts ${ }^{89}$ proposée par P. Briant ${ }^{90}$. Ce texte semble faire référence à une politique de colonisation agraire des Perses sur le plateau iranien, en Parthyène. Narrant l'offensive du roi séleucide Antiochos III contre le roi Parthe Arsakès II, Polybe décrit la route qu'il emprunte, rythmée par une chaîne d'oasis, le long du piémont de l'Elbourz, jusqu'à Hékatompylos. Selon P. Briant, Polybe décrit indiscutablement dans ce passage un réseau de qanâts, même s'il n'en comprend pas bien le fonctionnement. L'entretien de ces ouvrages, salutaires en l'occurrence pour Antiochos, apparaît fondamental pour favoriser les déplacements de l'armée et son approvisionnement en eau dans la région. P. Briant démontre que la politique perse a probablement reposé sur une exemption fiscale des agriculteurs participant à la mise en valeur du terroir par l'aménagement de qanâts. Il transparaît clairement d'après le texte de Polybe que l'administration perse faisait le choix, partout où cela était possible, de s'appuyer sur des infrastructures et des populations locales ${ }^{91}$. Pour revenir à Kharga et à El-Deir, il n'était donc nul besoin de recourir à une immigration perse pour mettre en œuvre une politique de mise en valeur globale de l'oasis : l'intervention de quelques spécialistes et le report sur les élites et les communautés locales du poids de l'investissement nécessaire, tant en main d'œuvre qu'en argent, semblent avoir été privilégiés ${ }^{92}$.

Ce type d'administration locale au sein de l'Empire achéménide n'est d'ailleurs pas sans rappeler la politique mise en ouvre au sein de l'Empire romain, telle que l'ont mise en évidence les travaux de C. Haselgrove et M. Millett : dépourvus d'infrastructures bureaucratiques suffisantes pour imposer une romanisation des cultures intégrées dans l'Empire, les Romains semblent s'être appuyés en Occident sur les élites locales et sur un système de reproduction sociale fondé sur l'émulation et sur des relations de clientèle similaires à celles qui étaient en place à Rome ${ }^{93}$. L'Empire se serait contenté d'étendre cette structure de participation et de dépendance en établissant des relations de clientèle entre Rome et les élites locales et se serait ainsi appuyé sur des structures sociales existantes avec une intervention militaire et administrative minimale. La culture romaine, dans ce contexte, est devenue le centre du système d'émulation préexistant. L'accès aux artefacts et l'adoption du mode de vie romains devinrent un des moyens par lesquels les

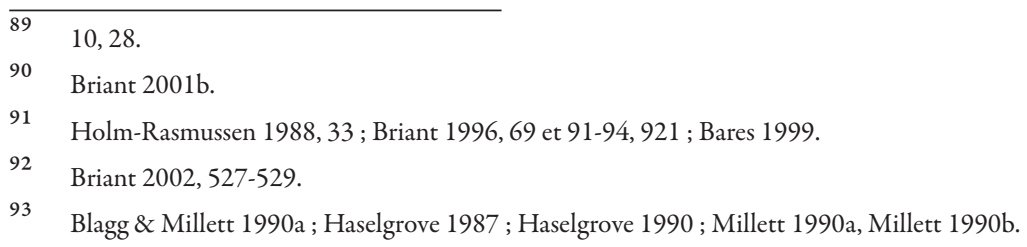


positions hiérarchiques des élites se constituèrent et se maintinrent. Le comportement des élites fut ensuite imité par d'autres couches de la société et donnèrent l'impulsion à des changements plus massifs dans l'architecture et la culture matérielle associée à la romanisation.

La présence dans les nécropoles d'El-Deir d'imitations de vaisselle de prestige achéménide, ainsi que la volonté de se distinguer par la construction de tombes à l'architecture spécifique, inspirée de celle des hauts fonctionnaires enterrés à Saqqara et Héliopolis, peut, nous semble-t-il, être associée à une telle démarche de distinction sociale, économique et politique. On a affaire, semble-t-il, à un petit groupe d'individus, même s'il est commun dans les nécropoles antiques de remarquer un effet de distorsion entre la faible population des nécropoles et celle, supposée plus nombreuse, des installations urbaines. Si l'on se réfère aux travaux de Fr. Barth et d'A. Cohen ${ }^{94}$ sur les stratégies individuelles et collectives de l'ethnicité, on retiendra que des individus peuvent adopter une catégorie ethnique nouvelle pour participer aux niches sociales ou écologiques auxquelles elles sont associées : les frontières ethniques sont donc perméables. Une telle approche amène à considérer l'ethnicité comme une stratégie individualiste. Pour Fr. Barth, les individus passent d'une catégorie ethnique à une autre pour faire avancer leurs intérêts politiques et économiques, ou pour minimiser leurs pertes. De la même manière, ils peuvent mettre en valeur ou dissimuler leur appartenance en fonction des avantages ou désavantages sociaux à tirer ${ }^{95}$. Pour étayer sa démonstration, Fr. Barth se réfère à une étude de G. Haaland sur des agriculteurs sédentaires soudanais, membres du groupe des Fur, qui sont pour certains amenés à changer d'identité ethnique et à adopter celle d'Arabes pasteurs nomades de la région, les Baggaras. Ce processus est conditionné par des circonstances économiques très spécifiques : il existe un fort contraste entre l'absence d'opportunité d'investissement de capital dans l'économie villageoise des Fur et les possibilités offertes chez les nomades Baggaras; le capital accumulé, les opportunités d'investissement et de croissance, sont déclencheurs d'abandon de leurs champs et de leurs villages par des familles Fur, qui décident de vivre la vie des Baggaras voisins. Si le changement s'avère une réussite sur le plan économique, ces Fur rejoignent de manière incidente les unités politiques (centralisées formellement, mais en réalité très lâches) des Baggaras. On peut s'interroger sur la possibilité d'un tel processus dans le cas d'El-Deir, d'autant plus que la

\footnotetext{
94 Cohen 1974b.

95 Barth 1969, 22-23; Haaland 1969.
} 
part de l'initiative privée et locale semble avoir toujours été prépondérante dans la gestion et le contrôle de l'eau en Égypte ${ }^{96}$.

Mais, contrairement au cas de l'Occident romain, où de telles stratégies de la part des élites ont fait des émules et où les formes matérielles nouvelles ont été ensuite empruntées par le reste de la société, les traits culturels «persisants» d'El-Deir disparaissent rapidement du répertoire des nécropoles. Sans doute, la conquête macédonienne et l'immigration massive de Grecs ont-elles pu contribuer à l'abandon de stratégies de distinction qui n'avaient plus lieu d'être.

Le matériel des secteurs postérieurs des nécropoles d'El-Deir présente une grande homogénéité, au moins jusqu'à l'époque chrétienne. Les traditions funéraires égyptiennes demeurent extrêmement prégnantes (cartonnages, mobilier, momification), même à l'époque chrétienne: ainsi, dans une des tombes du secteur ouest, où de nombreux marqueurs de la religion «nouvelle » ont été identifiés par M. Coudert, F. LetellierWillemin et Fr. Dunand ${ }^{97}$, on constate la permanence de pratiques de momification et un fréquent remploi de matériel traditionnel égyptien traditionnel «païen ». Un exemple en est une planchette provenant probablement d'un lit funéraire plus ancien, orné de scènes mythologiques et funéraires égyptiennes traditionnelles, sur lesquelles était déposée la momie d'une fillette à qui on a dû vouloir garantir la double protection des dieux païens et du dieu chrétien.

À l'ouest de la nécropole sud, dans un petit vallon, un bâtiment constitué de trois pièces communicantes a été identifié comme un atelier d'embaumeur. Son utilisation, à en juger par la céramique, semble avoir été de longue durée, depuis l'époque ptolémaïque jusqu'à l'époque copte. On sait que, pendant toute cette période, les embaumeurs étaient installés hors des villages, à proximité des nécropoles et il apparait ici que le même atelier a servi dans le contexte de la nécropole sud (perse et ptolémaïque, avec des réutilisations à l'époque romaine) puis dans celui de la nécropole ouest, chrétienne. La permanence est frappante, au-delà des mutations religieuses, de pratiques funéraires associées à une appartenance ethnique vécue comme égyptienne avant tout.

\footnotetext{
96 Comme l'a fait remarquer J. Manning, même à l'époque ptolémaïque, on note une absence frappante de bureaucratie locale spécialisée dans l'irrigation ; le contrôle de l'eau semble bien au contraire décentralisé : Manning 2002.

97 Dunand et al. 2008 ; Coudert 2012.
} 


\section{Bibliographie}

Abadie-Reynal, C.; S. Provost et P. Vipard, éd. (2011): Histoire des réseaux d'eau courante dans l'Antiquité - réparations, modifications, réutilisations, abandon, récupération, Rennes.

Agut-Labordère, D. (2005a) : «Le sens du Décret de Cambyse », Transeuphratène 29, 9-15.

Agut-Labordère, D. (2005b) : « Le titre du Décret de Cambyse », RdÉ 56, 45-53.

Agut-Labordère, D. (2008) : «Les frontières intérieures de la société militaire égyptienne : l'invasion de l'Égypte par Artaxerxès III à travers Diodore XVI.46.4-51.3 », Transeuphratène 35, 17-27.

Aston, D. A. et B. G. Aston (2003) : « The Dating of the Late Period Bes Vases », in : Redmount \& Keller 2003, 95-113.

Aston, D. ; B. Bader ; C. Gallorini ; P. Nicholson et S. Buckingham, éd. (2011) : Under the Potter's Tree. Studies on Ancient Egypt Presented to Janine Bourriau on the Occasion of her $70^{\text {th }}$ Birthday, OLA 204, Louvain.

Bagnall, R. S. ; P. Davoli et C. A. Hope, éd. (2012) : Oasis Papers 6. Proceedings of the Sixth International Conference of the Dakbleh Oasis Project, Oxford.

Balland, D., éd. (1992) : Les Eaux cachées. Études géographiques sur les galeries drainantes souterraines, Paris.

Bares, L. (1999) : The Shaft Tomb of Udjahorresnet at Abusir, Prague-Le Caire.

Barsanti, A. (1901) : « Rapports de M. Alexandre Barsanti sur les déblaiements opérés autour de la pyramide d'Ounas pendant les années 1899-1901 », ASAÉ 2, 244-257.

Barth, Fr., éd. (1969) : Ethnic Groups and Boundaries, Boston.

Bickel, S. et P. Tallet. (1997) : « La nécropole saite d'Héliopolis. Étude préliminaire », BIFAO 97, 67-90.

Blagg, T. et M. Millett. (1990a) : « Introduction », in : Blagg \& Millett 1990b, 1-4.

Blagg, T. et M. Millett, éd. (1990b) : The Early Roman Empire, Oxford.

Bourdieu, P. (1972) : Esquisse d'une théorie de la pratique, Genève.

Bousquet, B. (1996) : Tell Douch et sa région (désert libyque, Égypte). Géographie d’une limite de milieu à une frontière d'Empire, Le Caire.

Bousquet, B. (1999): «Les paysages d'irrigation dans les oasis du désert libyque (Égypte) pendant l'Antiquité », in : Peyras \& Tirologos 1999, 47-66.

Bousquet, B. (2001) : « Qanâts et géohistoire », in : Briant 2001a, 185-190.

Bousquet, B. et M. Robin (1999) : «Les oasis de Kysis. Essai de définition géo-archéologique », BIFAO 99, 21-40.

Bresciani, E. ; S. Pernigotti et G. Silvis (1977) : La Tomba di Ciennehebu, capo della flotta del re, Pise.

Briant, P. (1996) : Histoire de l'Empire perse, Paris. 
Briant, P., éd. (2001a) : Irrigation et drainage dans l'Antiquité, qanâts et canalisations souterraines en Iran, en Égypte et en Grèce, séminaire tenu au Collège de France, Persika 2, Paris.

Briant, P. (2001b) : « Polybe X.28 et les qanâts : le témoignage et ses limites », in : Briant 2001a, 15-40.

Briant, P. (2002) : « L'État, la terre et l'eau entre Nil et Syr-Darya : remarques introductives », Annales HSS 57/3, mai-juin, 517-529.

Briant, P. et M. Chauveau, éd. (2009) : Organisation des pouvoirs et contacts culturels dans les pays de l'empire achéménide, Actes du colloque organisé au Collège de France, 9-10 novembre 2007, Persika 14, Paris.

Briois, F.; B. Midant-Reynes et M. Wuttmann (2008) : Le Gisement épipaléolithique de ML1 à 'AynManâwir. Oasis de Kharga, Le Caire.

Chabaud, G. (2011) : Classement, déclassement, reclassement de l'Antiquité à nos jours, Limoges.

Charvat, P. (1980) : « The Bes jug. Its origin and development in Egypt », Z̈̈S 107, 46-52.

Chevereau, P.-M. (1985) : Prosopographie des cadres militaires égyptiens de la Basse Époque. Carrières militaires et carrières sacerdotales du XI' au II' siècle avant J.-C., Paris.

Cohen, A. (1974a) : «Introduction: the Lesson of Ethnicity », in : Cohen 1974b, ix-xxiv.

Cohen, A., éd. (1974b) : Urban Ethnicity, Londres.

Cooney, J. D. (1965) : « Persian influence in Late Art », JARCE 4, 39-48, pls. XXII-XXVIII.

Coudert, M. (2012) : « The Christian Necropolis of El-Deir in the North of Kharga Oasis », in : Bagnall et al. 2012, 451-458.

Cunliffe, B. W. ; C. Gosden et R. A. Joyce, éd. (2009) : Oxford Handbook of Archaeology, Oxford.

Defernez, C. (2003) : La Céramique d'époque perse à Tell el-Herr. Étude chrono-typologique et comparative, Lille.

Defernez, C. (2009) : «Les vases Bès à l'époque perse (Égypte-Levant). Essai de classification », in : Briant \& Chauveau 2009, 153-215.

Defernez, C. (2010) : « Quatre vases Bès provenant de Tell el-Herr (Nord-Sinaï). Description analytique et corrélation avec l'orfevvrerie de tradition achéménide », ENIM 3, 109-136.

Defernez, C. (2011) : «Four Bes Vases from Tell el-Herr (North-Sinaï): Analytical Description and Correlation with the Goldsmith's Art of Achaemenid tradition », in : Aston, Bader, Gallorini, Nicholson \& Buckingham 2011, 287-323.

Devereux, G. (1972) : Ethnopsychanalyse complémentariste, Paris.

Dunand, F. ; M. Coudert et F. Letellier-Willemin (2008) : « Découverte d'une nécropole chrétienne sur le site d'El Deir (Oasis de Kharga) », Études coptes, X. Douzième journée d'études de l'AFC, Maison de l'Orient, Lyon, 19, 20 et 21 mai 2005, Paris.

Dunand, F.; J.-L.Heim; N. Henein et R. Lichtenberg (1992): Douch I. La nécropole: exploration archéologique, Le Caire. 
Dunand, F. ; J.-L. Heim ; R. Lichtenberg ; S. Brones ; et F. Letellier-Willemin (2010) : El-Deir Nécropoles. 1. La nécropole sud, Paris.

Dunand, F.; J.-L. Heim ; R. Lichtenberg; S. Brones ; F. Letellier-Willemin et G. Tallet (2013) : El-Deir Nécropoles. 2. Les nécropoles nord et nord-est, Paris.

Dunand, F. et R. Lichtenberg (2008) : « Dix ans d'exploration des nécropoles d'El-Deir (oasis de Kharga). Un premier bilan », $C d E ́$ 83, 258-288.

El-Aguizy, O. (2010) : «Une nouvelle 'tombe-sarcophage à puits' à Saqqara », BIFAO 110, 13-34.

el-Sadeek, W. (1984) : Twenty-Sixth Dynasty Necropolis at Gizeh, Vienne.

Fossing, P. (1937) : « Drinking Bowls of glass and metal, from the Achaemenian time », Berytus 4, 121-29.

Gauthier, H. (1933) : « Découvertes récentes dans la nécropole saïte d'Héliopolis », ASAÉ 33, 27-53.

Goddio, F., éd. (2006) : Trésors engloutis d'Égypte, Paris.

Goudriaan, K. (1988) : Ethnicity in Ptolemaic Egypt, Amsterdam.

Grataloup, C., E. McCann et Y. Stolz (2006) : « La vie quotidienne dans la région canopique », in : Goddio 2006, 220-249.

Guédon, S., éd. (2012) : Entre Afrique et Égypte: relations et échanges entre les espaces au Sud de la Méditerranée à l'époque romaine. Actes du colloque international de l'Université de Limoges, 23 et 24 septembre 2010, Bordeaux.

Guidotti, C. (1983) : « Ipotesi di significato e tipologia dei vasi egizi di epoca tarda raffiguranti il dio Bes », EVO 6, 33-65.

Haaland, G. (1969) : « Economic determinants in ethnic processes », in : Barth 1969, 58-73.

Haselgrove, C. (1987) : « Culture Process on the Periphery: Belgic Gaul and Rome during the Late Republic and Early Empire », in : Rowlands, Larsen \& Kristiansen 1987, 104-124.

Haselgrove, C. (1990) : « The Romanization of Belgic Gaul: some archaeological perspectives », in : Blagg \& Millett 1990b, 45-71.

Hodder, I. (1989) : « This is not an article about material culture as text », Journal of Anthropological Archaeology, 8, 250-269.

Holm-Rasmussen, T. (1988) : « Collaboration in Early Achaemenid Egypt », Studies in Ancient History and Numismatics presented to Rudi Thomsen, Aarhus, 29-38.

Hope, C. A. ; M. A. J. Eccleston ; O. E. Kaper ; S. Marchand et D. Darnell (2000) : « Kegs and flasks from the Dakhleh Oasis », CCÉ 6, 190-234.

Jones, A. (2009) : « Into the future », in : Cunliffe, Gosden \& Joyce 2009, 89-114.

Jones, S. (1997) : The Archaeology of Ethnicity: Constructing Identities in the Past and Present, Londres-New York.

Kohl, P. L. et C. Fawcett, éd. (1996) : Nationalism, Politics and the Practice of Archaeology, Londres. 
Kossina, G. (1911) : Die Herkunft der Germaner, Leipzig.

Kristiansen, K. (2009) : « The discipline of archaeology », in : Cunliffe, Gosden \& Joyce 2009, 3-46.

Lauer, J.-Ph. (1954) : « La structure de la tombe de Hor à Saqqarah », ASAÉ 52, 133-136.

Lecuyot, G. (2000) : «La céramique du mastaba d'Akhethetep à Saqqara. Observations préliminaires », CCÉ 6, 235-261.

Leroi-Gourhan, A. (1982) : Les Racines du monde. Entretiens avec Claude-Henri Rocquet, Paris.

Leveau, Ph. (2002) : «Recension de P. Briant, Irrigation et drainage », Annales HSS 57-3 (mai-juin), 687689.

Lichtheim, M. (1973-1980) : Ancient Egyptian Literature, Berkeley.

Manning, J. G. (2002) : « Irrigation et État en Égypte ancienne », Annales HSS 57/3, mai-juin, 611-623.

Marchand, S. (1996) : « Douch, ‘Ayn Manawir (oasis de Kharga)», in : Wuttmann 1996, 415-431.

Marchand, S. (1997) : « Douch. 'Ayn Manawir (oasis de Kharga) », BCÉ 20, 45-47.

Marchand, S. (2000) : « Les segas des oasis datées des XXVII - XXIX dynasties et de l'époque ptolémaïque ancienne trouvées à Ayn Manâwîr (oasis de Kharga) et à Tebtynis (Fayoum) », CCÉ 6, 221-234.

Marchand, S. (2007) : « Les conteneurs de transport et de stockage de l'oasis de Kharga de la basse époque (XXVII $-\mathrm{XXX}^{\mathrm{e}}$ dynastie) $\gg, C C E ́$ 8, 489-502.

Marchand, S. (2011) : «La transposition céramique dans l'Égypte ancienne », in : Aston, Bader, Gallorini, Nicholson \& Buckingham 2011, 603-631.

Melikian-Chirvani, A. S. (1993) : « The International Achaemenid Style », Bulletin of the Asia Institute 7 , 111-130.

Menu, B. (1998) : Recherches sur l'histoire juridique, économique et sociale de l'ancienne Égypte. II, Le Caire.

Millett, M. (1990a) : «Romanization: historical issues and archaeological interpretation », in : Blagg \& Millett 1990b, 35-41.

Millett, M. (1990b) : The Romanization of Britain: an Essay in Archaeological Interpretation, Cambridge.

Peyras, J. et G. Tirologos, éd. (1999) : L'Afrique du Nord antique. Cultures et paysages. Colloque de Nantes, mai 1996, Besançon.

Planhol (de), X. (1992): «Les galeries drainantes souterraines: quelques problèmes généraux », in : Balland 1992, 129-142.

Porter, B. ; R. Moss et J. Malek (1974) : Topographical Bibliography of Ancient Egyptian Hieroglyphic Texts, Reliefs and Paintings. III, 2, Oxford ( $2^{\mathrm{e}}$ éd.).

Preucel, R.W. (2006) : Archaeological Semiotics, Oxford.

Preucel, R. et A. Bauer. (2001) : « Archaeological pragmatics », Norwegian Archaeological Review 34, 8596. 
Rabinowitz, I. (1956) : «Aramaic Inscriptions of the Fifth century BC from a North-Arab Shrine in Egypt », JNES 15, 1 (janvier), 1-9, pl. IV et V.

Reddé, M. (2012) : « Entre Afrique et Égypte. Les installations hydrauliques dans le désert et le prédésert à l'époque romaine », in : Guédon 2012, 145-146.

Redmount, C. A. et C. A. Keller, éd. (2003) : Egyptian Pottery. Proceedings of the 1990 Pottery Symposium at the University of California, Berkeley, ARF 58, Berkeley.

Rossi, C. (2000) : « Umm el-Dabadib, Roman Settlement in the Kharga Oasis: Description of the Visible Remains, with a Note on Ayn Amur », MDAIK 56, 335-352, pl. 35-39.

Rowlands, M. ; M. Larsen et K. Kristiansen, éd. (1987): Centre and Periphery in the Ancient World, Cambridge.

Schacht, I. (2003) : « A Preliminary Survey of the Ancient Qanat Systems of the Northern Kharga Oasis », MDAIK 59, 411-423.

Spalinger, A. J. (1978) : « The Reign of King Chabbash. An Interpretation », Z̈̈S 105, 142-154.

Stern, E. (1982) : Material Culture of the Land of the Bible in the Persian Period 538-332 BC. I, Warminster.

Stern, E. M. et B. Schlick-Nolte (1994) : Frühes Glas der alten Welt 1600 v. Chr.-50 n. Chr., Stuttgart.

Tallet, G. ; J.-P. Bravard et R. Garcier (2011) : « L'eau perdue d'une micro-oasis. Premiers résultats d'une prospection archéologique et géoarchéologique du système d'irrigation d'El-Deir, oasis de Kharga (Égypte) », in : Abadie-Reynal, Provost \& Vipard 2011, 173-188.

Tallet, G. ; J.-P. Bravard ; S. Guédon et A. Mostafa (2012) : « The Survey Project at El-Deir, Kharga Oasis: First Results, New Hypotheses », in : Bagnall et al. 2012, 349-361.

Tilley, C. (1999) : Metaphor and Material Culture, Oxford.

Trigger, B. G. (1977) : « Comments on Archaeological Classification and Ethnic Groups », Norwegian Archaeological Review 10, 20-23.

Trigger, B. G. (1996) : «Romanticism, Nationalism and Archaeology », in : Kohl \& Fawcett 1996, 263279.

Verner, M. (1989) : «La tombe d'Oudjahorresnê et le cimetière saïto-perse d'Abousir », BIFAO 89, 28390.

Verner, M. (2002) : Abusir-Realm of Osiris, Le Caire.

Vivian, C. (2009) : The Western Desert of Egypt: An Explorer's Handbook, Le Caire.

Watanabe, M. ; K. Kogawa ; T. Sugimura ; T. Nakano ; T. Tsukamoto et H. Kamei (2010) : « Interpretation of Water Environment around El-Zayyan Temple in Kharga Oasis, Western Desert, Egypt from a Tentative Environmental Map Based on ALOS Pan-Sharpened Imagery », Journal of The Remote Sensing Society of Japan 30/1, 11-18.

Wessetzki, V. (1991) : « Fragen zum Verhalten der mit den Persern zusammenarbeitenden Ägypter », GM $124,83-89$. 
Wuttmann, M. (2001) : « Les qanâts de Ayn-Manâwîr (oasis de Kharga, Égypte) », in : Briant 2001a, 109135.

Wuttmann, M. (2003) : « 'Ayn Manawir », ÉA 22, 36-37.

Wuttmann, M.; H. Barakat ; B. Bousquet ; M. Chauveau ; T. Gonon ; S. Marchand ; M. Robin et A. Schweitzer (1998) : «'Ayn Manâwîr (oasis de Kharga). Deuxième rapport préliminaire », BIFAO $98,367-462$.

Wuttmann, M. ; B. Bousquet ; M. Chauveau ; P. Dils ; S. Marchand ; A. Schweitzer et L. Volay (1996) : « Premier rapport préliminaire des travaux sur le site de 'Ayn Manâwîr (oasis de Kharga) », BIFAO $96,385-451$. 